\title{
The Choline-binding Protein PspC of Streptococcus pneumoniae Interacts with the C-terminal Heparin-binding Domain of Vitronectin ${ }^{*[5}$
}

Received for publication, December 8, 2012, and in revised form, April 10, 2013 Published, JBC Papers in Press, April 19, 2013, DOI 10.1074/jbc.M112.443507

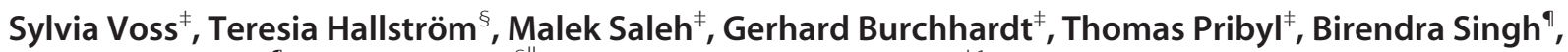
Kristian Riesbeck", Peter F. Zipfel ${ }^{\S \|}$, and Sven Hammerschmidt ${ }^{\ddagger 1}$

From the ${ }^{\ddagger}$ Department of Genetics of Microorganisms, Interfaculty Institute for Genetics and Functional Genomics, University of Greifswald, D-17487 Greifswald, Germany, the ${ }^{\S}$ Department of Infection Biology, Hans Knoell Institute, Leibniz Institute for Natural Product Research and Infection Biology, D-07745 Jena, Germany, the "Institute for Microbiology, Friedrich Schiller University, D-07743 Jena, Germany, and "Medical Microbiology, Department of Laboratory Medicine, Lund University, Skåne University Hospital, SE-205 02 Malmö, Sweden

Background: Adhesins are essential for pneumococcal colonization and pathogenesis.

Results: PspC, identified as a vitronectin-binding protein, interacts with the C-terminal heparin-binding domain of vitronectin, and when bound to PspC, it retains complement inhibitory function.

Conclusion: PspC is an adhesin for vitronectin, and the PspC-vitronectin interaction inhibits immune attack.

Significance: The PspC-vitronectin interaction provides new insights into pneumococcal adhesion and complement inhibition.

Adherence of Streptococcus pneumoniae is directly mediated by interactions of adhesins with eukaryotic cellular receptors or indirectly by exploiting matrix and serum proteins as molecular bridges. Pneumococci engage vitronectin, the human adhesive glycoprotein and complement inhibitor, to facilitate attachment to epithelial cells of the mucosal cavity, thereby modulating host cell signaling. In this study, we identified PspC as a vitronectin-binding protein interacting with the $\mathrm{C}$-terminal heparin-binding domain of vitronectin. PspC is a multifunctional surface-exposed choline-binding protein displaying various adhesive properties. Vitronectin binding required the $\mathbf{R}$ domains in the mature PspC protein, which are also essential for the interaction with the ectodomain of the polymeric immunoglobulin receptor and secretory IgA. Consequently, secretory IgA competitively inhibited binding of vitronectin to purified PspC and to PspC-expressing pneumococci. In contrast, Factor $\mathrm{H}$, which binds to the $\mathrm{N}$-terminal part of mature PspC molecules, did not interfere with the PspC-vitronectin interaction. Using a series of vitronectin peptides, the C-terminal heparinbinding domain was shown to be essential for the interaction of soluble vitronectin with PspC. Binding experiments with immobilized vitronectin suggested a region $\mathrm{N}$-terminal to the identified heparin-binding domain as an additional binding region for PspC, suggesting that soluble, immobilized, as well as cellularly bound vitronectin possesses different conformations. Finally, vitronectin bound to $\mathrm{PspC}$ was functionally active and inhibited the deposition of the terminal complement complex. In conclusion, this study identifies and characterizes (on the molecular

\footnotetext{
* This work was supported by Grants DFG HA 3125/4-2 and the DFG-GRK840 from the Deutsche Forschungsgemeinschaft (to S. H.).

5 This article contains supplemental Figs. S1-S5.

${ }^{1}$ To whom correspondence should be addressed: Dept. of Genetics of Microorganisms, Interfaculty Institute for Genetics and Functional Genomics, Ernst Moritz Arndt University Greifswald, Friedrich-Ludwig-Jahn-Strasse 15A, 17487 Greifswald, Germany, Tel.: 0049-3834-864161, Fax: 0049-3834864172, E-mail: sven.hammerschmidt@uni-greifswald.de.
}

level) the interaction between the pneumococcal adhesin PspC and the human glycoprotein vitronectin.

Pneumococci (Streptococcus pneumoniae) are Gram-positive bacteria usually transmitted by aerosols and asymptomatically colonizing the human upper respiratory tract. Especially in children, the elderly, and immunocompromised adults, pneumococci can cause mild local infections such as sinusitis or otitis media and also severe life-threatening diseases, including community-acquired pneumonia, pneumococcal meningitis, and sepsis (1). After surmounting the airway mucus and initial loose attachment to the host cell surface, nasopharyngeal colonization by $S$. pneumoniae proceeds by intimate contact to the respiratory epithelium. Therefore, pneumococci express an armamentarium of surface-exposed adhesins. These adhesins interact with host cellular receptors directly or indirectly by targeting extracellular matrix or acquiring human serum proteins, thereby linking pneumococci to eukaryotic cell receptors or professional phagocytes (2-8). Adhesive properties are known for a number of pneumococcal surface proteins recognizing plasmin(ogen), fibronectin, thrombospondin-1, and vitronectin $(8-17)$. A subpopulation of pneumococci produces pili, encoded by the pilus islet (PI)-1 or PI-2, and at least the RrgA of PI-1 functions as an adhesin (17-20). However, one of the most important adhesins of $S$. pneumoniae is the pneumococcal surface protein $\mathrm{C}$ (PspC, also referred to as CbpA or SpsA), which belongs to the family of pneumococcal cholinebinding proteins. Eleven different PspC subtypes are classified into two subgroups, depending on their anchorage to the bacterial cell envelope. The classical PspC proteins (subtypes 1-6, members of subgroup I) contain a conserved C-terminal choline-binding domain with a variable number of 7-13 repeats, each of 20 amino acid residues. The choline-binding domain enables a noncovalent attachment to phosphorylcholine moieties on the bacterial surface. In contrast, PspC-like proteins 


\section{Pneumococcal PspC Binds Vitronectin}

(subtypes 7-11, members of subgroup II) possess the C-terminal sortase recognition motif LPXTG and are therefore covalently linked to the bacterial peptidoglycan via the sortase-catalyzed transpeptidation reaction. PspC proteins of subgroup I share high similarities in sequence, structure, and organization of the N-terminal region: the 37-amino acid leader peptide is followed by the Factor $\mathrm{H}$-binding domain, one or two single repeated domains (termed R1 and R2), and a proline-rich region $(21,22)$. Pneumococcal adhesion and internalization into respiratory epithelial cells are primarily accomplished by the unique human-specific binding of PspC to the secretory component $(\mathrm{SC})$ of the polymeric Ig receptor $(\mathrm{pIgR})(23,24)$. A conserved hexapeptide motif contained once in each $\mathrm{R}$ domain within PspC directly interacts with the human Ig-like domains D3 and D4 of the SC (either soluble or bound to the pIgR or as part of the mucosal secretory IgA) $(24-26)$. The PspC-pIgR interaction mediates adherence and activation of signal transduction cascades resulting in the uptake and transcytosis of pneumococci across the epithelial barrier $(2,25,26)$. Furthermore, PspC interacts directly with a laminin-specific integrinreceptor ubiquitously expressed on vascular endothelial cells, contributing to invasive diseases, including pneumococcal meningitis (27). In addition, PspC recruits the complement inhibitor proteins $\mathrm{C} 4 \mathrm{~b}$-binding protein and Factor $\mathrm{H}$ to the bacterial surface $(28,29)$. The interaction sites were mapped to a 121 -amino acid sequence in the $\mathrm{N}$-terminal part of the PspC protein and to the short consensus repeats $8-11$ and short consensus repeats $19-20$ of Factor $\mathrm{H}(2,30)$. This interplay enables pneumococci to effectively evade the host immune attack and to control complement effector functions by inhibiting the C3 convertase activity of the alternative pathway (31). Moreover, Factor $\mathrm{H}$ bound to the pneumococcal surface facilitates adherence to human integrins of epithelial cells $(2,30)$.

Pneumococci are able to recruit soluble vitronectin $(\mathrm{Vn})^{2}$ to their surface. However, only host cell-bound vitronectin facilitates pneumococcal adherence to and invasion into respiratory epithelial cells. Vitronectin circulates in human plasma as a folded monomer of $75 \mathrm{kDa}$, existing either as a single-chain protein or as a two-chain disulfide-linked polypeptide $(65+10$ $\mathrm{kDa}$ ), and it modulates the complement, fibrinolytic, and coagulation system $(32,33)$. However, in its multimeric unfolded form, vitronectin can efficiently bind to and incorporate into the extracellular matrix (ECM) of various human tissues supporting cell adhesion and differentiation, as well as regulating ECM composition and stability $(32,33)$. The interaction sites for a vast variety of binding partners are located in different vitronectin domains. The N-terminal part includes a somatomedin B domain and an RGD motif that allows attachment of vitronectin to the integrin receptors $\alpha_{\mathrm{v}} \beta_{3}, \alpha_{\mathrm{v}} \beta_{1}$, and $\alpha_{\mathrm{v}} \beta_{5}$ (34). In addition to four hemopexin-type repeats, vitronectin consists of three heparin-binding domains (HBDs), of which the most $\mathrm{C}$-terminal one mediates binding to proteoglycans and is

\footnotetext{
${ }^{2}$ The abbreviations used are: $V n$, vitronectin; $E C M$, extracellular matrix; $H B D$, heparin-binding domain; TCC, terminal complement complex; $\mathrm{PE}$, protein $\mathrm{E}$; SC, secretory component; GMFI, geometric mean fluorescence intensity; SPR, surface plasmon resonance; slgA, secretory IgA; SC, secretory component; plgR, polymeric Ig receptor; OPD, 1,2-phenylenediamine dihydrochloride.
}

involved in ligand-induced multimerization of the molecule $(33,35)$. Gram-negative pathogenic bacteria recruit plasma vitronectin to prevent the assembly and deposition of the terminal complement complex (TCC) and subsequent bacterial lysis. Recently, Haemophilus influenzae protein E (PE) was identified as a vitronectin-binding protein, and it was demonstrated that $\mathrm{PE}$ exclusively interacts with the $\mathrm{C}$-terminal heparin-binding domain of vitronectin (36-38). Gram-positive pathogens commonly utilize ECM-associated vitronectin for an efficient adhesion to host epithelial cells and subsequent internalization (39). Binding of S. pneumoniae to host cell-bound vitronectin particularly engages the $\alpha_{\mathrm{v}} \beta_{3}$-integrin receptor triggering the activation of the integrin-linked kinase in a PI3K-dependent manner. In addition, upon infection of host cells, pneumococci induce protein kinase B (Akt) activation, resulting in a rearrangement of the cellular actin cytoskeleton and formation of microspikelike membrane protrusions in which pneumococci are subsequently trapped. The pneumococcal binding site in vitronectin was restricted to the heparin-binding domain(s) of vitronectin (4). However, as mentioned above, the pneumococcal surface factor that binds human vitronectin has not yet been described.

In this study, we identified the multifunctional PspC of S. pneumoniae as a human vitronectin-binding protein. In addition, we demonstrated that vitronectin preferentially binds to PspC subtypes of S. pneumoniae consisting of two SC-binding regions, termed $\mathrm{R}$ domains, located in the mature N-terminal part of PspC. We localized the major binding site of PspC to the C-terminal heparin-binding domain of vitronectin. The data further suggested that a region $\mathrm{N}$-terminal to the $\mathrm{C}$-terminal HBD confers binding of pneumococci via PspC to immobilized vitronectin. Finally, we confirmed that vitronectin bound to $\mathrm{PspC}$ is functionally active and can inhibit the terminal complement pathway.

\section{EXPERIMENTAL PROCEDURES}

Bacterial Strains, Culture Conditions, and Pneumococcal Mutant Construction-S. pneumoniae were cultured on solid blood agar plates (Oxoid, Germany) at $37{ }^{\circ} \mathrm{C}$ and $5 \% \mathrm{CO}_{2}$ or in liquid Todd-Hewitt-broth (Roth, Germany) supplemented with $0.5 \%$ yeast extract (Roth) to mid-log phase $\left(3.5-4 \times 10^{8}\right.$ $\mathrm{cfu} / \mathrm{ml})$. Pneumococcal wild-type strains, isogenic mutants deficient for the capsular polysaccharide, PspC, functional lipoproteins, or LPXTG-anchored proteins, respectively, are listed in Table 1. Primers used to amplify DNA fragments are listed in Table 2. Pneumococcal mutants in R800 and D39 scps were generated by insertion deletion mutagenesis of the respective genes. For the construction of R800 $\Delta p s p C$, the pQSV22 plasmid was constructed by ligation of the SpeI-linearized and blunt-ended $p s p C$ gene, which was formerly cloned into pQE-30 (23), with the EcoRV-digested spectinomycin resistance gene aad9 (Table 1). To construct the mutant D39 $\Delta$ cps $\Delta l g t$, a 1940-bp fragment containing the lgt gene region interrupted by an $\mathrm{erm} B$ gene cassette was PCR-amplified from the genomic DNA of $S$. pneumoniae R6 $\lg$ t with the primers lgt1fw and lgt7rev and cloned into the TA-cloning vector pGEM-T Easy resulting in plasmid p552 (Table 1). For the construction of D $39 \Delta c p s \Delta l s p$, the $l s p$ gene region was amplified from D39 $\Delta$ cps genomic DNA using the primers lsp1fw and lsp4rev and cloned into pGEM-T Easy. By inverse PCR, an 
TABLE 1

Strains and plasmids used in this study

The abbreviations used are as follows: Amp, ampicillin; Km, kanamycin; Erm, erythromycin; Spc, spectinomycin; r, resistant.

\begin{tabular}{|c|c|c|}
\hline Strain or plasmid & Characteristics & Ref./source \\
\hline \multicolumn{3}{|l|}{ S. pneumoniae } \\
\hline P34 & Serotype 1 & ATCC33400 \\
\hline P37 & Serotype $35 \mathrm{~A}$ & NCTC10319 \\
\hline P137 & $\mathrm{R} 6 \Delta \operatorname{lgt}\left(\Delta \operatorname{lgt}:: \mathrm{Erm}^{\mathrm{r}}\right)$ & 58 \\
\hline P173 (R800) & Nonencapsulated derivative of R36A & 59 \\
\hline P257 (D39) & Serotype 2 & NCTC7466 \\
\hline P261 (TIGR4) & Serotype 4 & 60 \\
\hline PN107 & TIGR4 $\Delta c p s\left(\Delta c p s:: \mathrm{Km}^{\mathrm{r}}\right)$ & 30 \\
\hline PN111 & $\mathrm{D} 39 \Delta c p s\left(\Delta c p s:: \mathrm{Km}^{\mathrm{r}}\right)$ & 15 \\
\hline PN194 & $\mathrm{D} 39 \Delta c p s \Delta p s p C\left(\Delta p s p C:: \mathrm{Erm}^{\mathrm{r}}\right)$ & This study \\
\hline PN220 & $\mathrm{D} 39 \Delta \operatorname{cps} \Delta \operatorname{lgt}\left(\Delta \operatorname{lgt::\text {Erm}^{\mathrm {r}})}\right.$ & This study \\
\hline PN231 & $\mathrm{D} 39 \Delta c p s \Delta l s p\left(\Delta l s p:: \mathrm{Spc}^{\mathrm{r}}\right)$ & This study \\
\hline PN299 & $\mathrm{D} 39 \Delta \operatorname{cps} \Delta s r t A\left(\Delta s r t A:: \mathrm{Erm}^{\mathrm{r}}\right)$ & This study \\
\hline PN362 & $\mathrm{R} 800 \Delta p s p C\left(\Delta p s p C:: \mathrm{Spc}^{\mathrm{r}}\right)$ & This study \\
\hline \multicolumn{3}{|l|}{ Lactococcus lactis } \\
\hline Lacto 2 & Strain MG1363, plasmid-free and prophage-cured derivative of NCDO 712 & 61 \\
\hline Lacto 22 & Lacto 2 pPspC3 & This study \\
\hline Lacto 23 & Lacto 2 pPspC2 & This study \\
\hline \multicolumn{3}{|l|}{ E. coli } \\
\hline $\mathrm{DH} 5 \alpha$ & $\Delta($ lac $) U 169$ endA1 gyrA46 hsdR17 $\Phi 80 \Delta(\mathrm{lacZ}) \mathrm{M} 15$ recA1 relA1 supE44 thi-1 & Novagen \\
\hline \multicolumn{3}{|l|}{ Plasmids } \\
\hline pGEM $^{\circledR}-\mathrm{T}$ easy & TA cloning vector for PCR products and blue-white colony selection, $\mathrm{Amp}^{\mathrm{r}}$ & Promega \\
\hline pBlue-Script II TKS $(-)$ & TA cloning vector for PCR products and blue-white colony selection, Amp ${ }^{\mathrm{r}}$ & 62 \\
\hline pQSH22 & pQE-30 with $p s p C$ gene region from S. pneumoniae ATCC33400, Amp ${ }^{\mathrm{r}}$ & 23 \\
\hline pQSV22spec & pQSH22 with $p s p C 5^{\prime}$ and $3^{\prime}$ flanking regions for mutagenesis, $\mathrm{Amp}^{\mathrm{r}}, \mathrm{Spc}^{\mathrm{r}}$ & This study \\
\hline p552 & $\begin{array}{l}\text { pGEM-T derivative with spd_1243 5' - and 3'flanking regions for } \\
\text { mutagenesis, Amp }{ }^{\mathrm{r}}, \mathrm{Erm}^{\mathrm{r}}\end{array}$ & This study \\
\hline p556 & $\begin{array}{l}\text { pGEM-T derivative with spd_08195' - and 3'flanking regions for } \\
\text { mutagenesis, } \mathrm{Amp}^{\mathrm{r}}, \mathrm{Spc}^{\mathrm{r}}\end{array}$ & This study \\
\hline p745 & $\begin{array}{l}\text { pBlue-Script derivative with } s p_{-} 12185^{\prime} \text { - and } 3^{\prime} \text { flanking regions for } \\
\text { mutagenesis, } \mathrm{Amp}^{\mathrm{r}}, \mathrm{Erm}^{\mathrm{r}}\end{array}$ & This study \\
\hline pGKK1 & $\begin{array}{l}\text { pMSP3535 derivative expressing truncated pspC3.4 from S. pneumoniae } \\
\text { TIGR4 under PnisA promoter control, Erm }{ }^{\mathrm{r}}\end{array}$ & 41 \\
\hline pPspC2 & $\begin{array}{l}\text { pMSP3535 derivative expressing } p s p C 2 \text { from S. pneumoniae ATCC33400 } \\
\text { under PnisA promoter control, Erm }{ }^{\mathrm{r}}\end{array}$ & This study \\
\hline pPspC3 & $\begin{array}{l}\text { pMSP3535 derivative expressing pspC3 from S. pneumoniae D39 under } \\
\text { PnisA promoter control, Erm }{ }^{\mathrm{r}}\end{array}$ & This study \\
\hline
\end{tabular}

\section{TABLE 2}

Primers used in this study

\begin{tabular}{|c|c|c|}
\hline Primer & Sequence $^{a}$ & $\begin{array}{l}\text { Restriction } \\
\text { site }\end{array}$ \\
\hline SpcforClaI & 5'-GCGCGCGCGCGCATCGATATCGATTTTCGTTCGTGAATAC-3' & ClaI \\
\hline SpcrevClaI & 5'-GCGCGCGCGCGCATCGATAATTAGAATGAAATATTTCCC-3' & ClaI \\
\hline EryfwdAscI & 5'-CGCGCGCGCGGGCGCGCCACGGTTCGTGTTCGTGCTG-3' & AscI \\
\hline EryrevAscI & 5'-CGCGCGCGCGGGCGCGCCCGTAGGCGCTAGGGACCTC-3' & AscI \\
\hline lgt1fw & $5^{\prime}$-GCCGTGCAGCTACCAGTCG-3' & None \\
\hline lgt7rev & $5^{\prime}$-CATCGATGACACGACCAAGC-3' & None \\
\hline lsplfwd & 5'-CGGCCTTTTCAGAGCGCTATCC-3' & None \\
\hline lsp4rev & 5'-CCTTGAGTTCTTGGGCAAGTGC-3' & None \\
\hline lsp2rev & 5'-ATCGATCATGACTTCTACGAAGAGAGTC-3' & ClaI \\
\hline lsp3fw & $5^{\prime}$-ATCGATGTGGCAGATAGCTATC-3' & ClaI \\
\hline SP_1218StartFor & $5^{\prime}$-AAAGTAATGCGCCTGGATCA-3' & None \\
\hline SP_1218StartRev & 5'-AAAAGGCGCGCCCATTACTTGCTCGCGTTTCA-3' & AscI \\
\hline SP_1218EndFor & 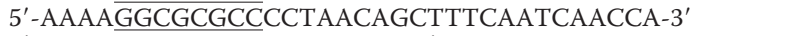 & AscI \\
\hline SP_1218EndRev & 5'-AAGTGACCAACTCGGCATTC-3' & None \\
\hline N-PspC & 5'-CGATGGATCCGTTTGCATCAAAAAGCGAAG-3' & BamHI \\
\hline PspCrev & 5' - GCGCCCATGGTTTTTCTTTAACTTTATCTTCTTCTGCTGC-3' & NcoI \\
\hline
\end{tabular}

${ }^{a}$ Restriction sites are underlined.

internal part of the lsp gene was deleted using the primer pair lsp2rev and lsp3fw with incorporated ClaI restriction sites for subsequent ligation with the aad 9 gene, amplified with the primers SpcforClaI and SpcrevClaI, with the PCR product. This resulted in plasmid p556 (Table 1). To construct a mutant deficient for surface expression of LPXTG-anchored proteins in D39 $\Delta$ cps, the $s r t A$ gene region (1350 bp) was amplified from TIGR4 genomic DNA using the primers SP_1218StartFor and SP_1218EndRev. After cloning the PCR product into pBlue-Script II TKS(-), the primers SP_1218StartRev and SP_1218EndFor, which incorporated AscI restriction sites, were used to replace an internal sequence in $s r t A$ with an $\operatorname{erm} B$ gene cassette amplified with the primer pair EryfwdAscI and EryrevAscI. This resulted in plasmid p745 (Table 1).

S. pneumoniae strains were transformed either with the plasmid constructs or linear DNA fragments amplified by PCR in the presence of competence-stimulating peptide- 1 as described previously (40). Gene knockouts of pneumococcal transformants were verified by PCR and, where applicable, by flow cytometric analysis. 


\section{Pneumococcal PspC Binds Vitronectin}

Escherichia coli strains, listed in Table 1, were cultivated at $30{ }^{\circ} \mathrm{C}$ on Luria-Bertani agar or broth (Roth) supplemented with appropriate antibiotics. Transformation of E. coli strains with plasmid DNA was carried out with $\mathrm{CaCl}_{2}$-treated competent cells according to standard procedures.

Culture Conditions, Cloning, and Recombinant Procedures in Lactococcus lactis-L. lactis MG1363 was grown statically at $30{ }^{\circ} \mathrm{C}$ in M17 agar or broth (Oxoid) supplemented with 0.5\% glucose and $5 \mu \mathrm{g} / \mathrm{ml}$ erythromycin. Transformation with plasmid DNA was performed by electroporation as described recently (41). The recombinant pGKK1 plasmid was used for the inducible extracellular expression of PspC in L. lactis (41). To generate heterologous L. lactis expressing other PspC subtypes, the desired $p s p C$ DNA fragments were amplified by PCR using the chromosomal DNA of strain $S$. pneumoniae ATCC33400 (PspC2) or D39 (PspC3). DNA was amplified with the primers N-PspC and PspCrev containing incorporated BamHI and NcoI restriction sites, respectively. The PCR products were digested with BamHI and NcoI (New England Biolabs) and cloned into the similarly digested pGKK1 vector to generate the $\mathrm{pPspC} 2$ or $\mathrm{pPspC} 3$ plasmid, respectively. The coding sequence of $p s p C$ was verified by DNA sequencing (Eurofins MWG Operon, Germany). Sequence comparisons were performed with the Blast programs from the NCBI database. The recombinant plasmid was first selected after transformation into E. coli DH5 $\alpha$ and then transformed into electrocompetent L. lactis (Table 1). Expression of PspC was induced by adding nisin $(0.1 \mu \mathrm{g} / \mathrm{ml})$ to mid-log grown recombinant lactococci.

Reagents and Antibodies-DNA and protein markers were from Fermentas (Thermo Fisher Scientific Inc., Leicestershire, UK). Coomassie Brilliant Blue R-250 and bovine serum albumin (BSA) were purchased from Roth. Heparin (potassium salt) and HRP-conjugated rabbit anti-IgA antibodies were obtained from ICN Biomedicals (Aurora, OH). Multimeric vitronectin was purchased from Millipore (Merck). Biotin-labeled multimeric vitronectin was provided by Loxo (Germany). Recombinant $\mathrm{C}$-terminally $\mathrm{His}_{6}$-tagged multimeric vitronectin fragments were heterologously expressed in HEK293T cells and purified as described (38). Fluorescein isothiocyanate (FITC), choline chloride, human secretory IgA, paraformaldehyde, nisin, heparan sulfate, chondroitin sulfate A, and Bradford reagent were purchased from Sigma. Human Factor $\mathrm{H}$ was provided by Calbiochem (Merck) or Complement Technology (Tyler, TX). Rabbit anti-human vitronectin antibodies were purchased from Abcam (Cambridge, UK) or Complement Technology. Goat anti-human Factor $\mathrm{H}$ antibodies and the complement inhibitor proteins C5b-6, C7, C8, and C9 were provided by Complement Technology. AlexaFluor488-conjugated goat anti-rabbit IgG was provided by Invitrogen. HRPconjugated swine anti-rabbit antibodies, HRP-conjugated rabbit anti-goat antibodies, mouse anti-human C5b-9 monoclonal antibodies, and HRP-conjugated swine anti-mouse antibodies were purchased from Dakopatts (Glostrup, Denmark). Cy5conjugated goat anti-mouse antibodies and AlexaFluor488conjugated streptavidin were provided by Dianova (Germany). The ELISA substrate 1,2-phenylenediamine dihydrochloride (OPD) was purchased from DakoCytomation (Glostrup, Den- mark). Anti-SH2 and anti-SH12 antiserum were generated by immunization of mice with the $\mathrm{PspC}-\mathrm{SH} 2$ or $-\mathrm{SH} 12$ protein derivative according to standard methods. Mouse control serum was generated by a similar immunization procedure without protein.

Expression of $\mathrm{N}$-terminally $\mathrm{His}_{6}$-tagged Proteins and Protein Purification-N-terminally $\mathrm{His}_{6}$-tagged PspC proteins used in this study have been described earlier (Fig. 3A) (24, 25). Briefly, the recombinant $\mathrm{His}_{6}$-tagged PspC proteins represent PspC group 2, which is expressed by strain ATCC 33400 (serotype 1), or PspC group 3 expressed by strain NCTC 10319 (serotype 35A) and D39 (serotype 2), respectively. The $\mathrm{His}_{6}$-tagged fusion proteins were purified by $\mathrm{Ni}^{2+}$ affinity chromatography either with the Protino nickel prepacked column kit according to the manufacturer's instructions (Macherey-Nagel) or with His Trap FF crude columns (GE Healthcare) and Äktapurifier (GE Healthcare). Proteins were dialyzed against appropriate buffers before experiments and concentrations were measured by UV absorbance (280 nm) using a Nano-drop spectrophotometer (Thermo Scientific, Wilmington, DE). The concentrations were also verified using a Bradford protein assay. The purity of expressed proteins was controlled on SDS-PAGE stained with Coomassie Brilliant Blue R-250 or silver nitrate.

Flow Cytometric Analysis-To detect vitronectin bound to pneumococci, $1 \times 10^{8}$ bacteria were incubated with vitronectin or recombinant vitronectin peptides, respectively, in $100 \mu \mathrm{l}$ of Dulbecco's modified Eagle's medium (DMEM, 1 g/liter glucose; PAA Laboratories) for $45 \mathrm{~min}$ at $37^{\circ} \mathrm{C}$ in 96-well plates (Greiner, Germany), washed, and incubated with anti-human vitronectin antibodies. After washing, bacteria were incubated with AlexaFluor488-conjugated anti-rabbit IgG. To inhibit vitronectin binding, pneumococci were incubated with vitronectin $(2.5 \mu \mathrm{g} / \mathrm{ml})$ in DMEM supplemented with $5 \%$ choline chloride. In further inhibition experiments, pneumococci were incubated with secretory IgA (sIgA), anti-PspC mouse antiserum, or mouse control serum (both at a dilution of 1:50) for 15 min prior to the addition of vitronectin $(1 \mu \mathrm{g} / \mathrm{ml})$, or vitronectin $(1 \mu \mathrm{g} / \mathrm{ml})$ was incubated for $15 \mathrm{~min}$ in presence of purified His $_{6}$-tagged PspC-SH13 and added to the pneumococci. After washing, bacteria were incubated with anti-human vitronectin antibodies, and subsequently incubated with AlexaFluor488conjugated anti-rabbit IgG. In inhibition experiments with Factor $\mathrm{H}$, pneumococci were incubated for 15 min with Factor $\mathrm{H}$; thereafter, biotin-labeled vitronectin $(1 \mu \mathrm{g} / \mathrm{ml})$ was added to the pneumococci. After extensive washing, bacteria were incubated with AlexaFluor488-conjugated streptavidin $(2 \mu \mathrm{g} / \mathrm{ml})$. Finally, bacteria were washed and fixed using $1 \%$ paraformaldehyde overnight at $4{ }^{\circ} \mathrm{C}$. The samples were analyzed by flow cytometry using a FACSCalibur ${ }^{\text {TM }}$ (BD Biosciences). Data acquisition was conducted using the CellQuestPro Software 6.0 (BD Biosciences), and data analysis was performed using the WinMDI Software 2.9 (The Scripps Research Institute). The bacteria were detected and gated as described previously $(4,15)$, and the results of protein binding to pneumococci are shown as the total fluorescence (geometric mean fluorescence intensity (GMFI) multiplied with the percentage of AlexaFluor488-labeled and gated events) or as percentage of vitronectin binding. 
Enzyme-linked Immunosorbent Assay (ELISA)-Microtiter plates (F96, Polysorb ${ }^{\text {TM }}$, Nunc-Immuno Module) were coated with $100 \mu \mathrm{l}$ of $5 \mu \mathrm{g} / \mathrm{ml}$ S. pneumoniae PspC constructs PspCSH2, SH3, SM1, SM2, SH12, SH13, H. influenzae PE, or Staphylococcus aureus binder of IgG (Sbi), respectively, overnight at $4{ }^{\circ} \mathrm{C}$. The plates were washed four times with $0.05 \%$ Tween ${ }^{\circledR}$ 20/PBS, pH 7.4, and blocked for $1 \mathrm{~h}$ at room temperature (RT) with $0.1 \%$ Tween ${ }^{\circledR} 20 /$ PBS supplemented with $2 \%$ BSA (blocking buffer). After washing, the plates were incubated for $1 \mathrm{~h}$ at RT with vitronectin $(100 \mu \mathrm{l}$ of $0-40 \mu \mathrm{g} / \mathrm{ml})$ or the various recombinant vitronectin constructs $(100 \mu \mathrm{l}$ of $5 \mu \mathrm{g} / \mathrm{ml})$ diluted in blocking buffer. Thereafter, the wells were washed and incubated with rabbit anti-human vitronectin antibodies (1:1000 in blocking buffer) followed by HRP-conjugated anti-rabbit antibodies (1:1000 in blocking buffer). The reaction was developed with OPD, and the absorbance was measured at $492 \mathrm{~nm}$. In inhibition assays, immobilized SH13 was incubated with increasing concentrations of $\mathrm{NaCl}(100 \mu \mathrm{l}$ of $0-1.0 \mathrm{M})$, heparin $(100 \mu \mathrm{l}$ of $0-5000 \mu \mathrm{g} / \mathrm{ml})$, heparan sulfate or chondroitin sulfate A (both $100 \mu \mathrm{l}$ of $0-1000 \mu \mathrm{g} / \mathrm{ml}$ ), and a constant concentration of vitronectin $(5 \mu \mathrm{g} / \mathrm{ml})$. Because Factor $\mathrm{H}$ does not bind to the recombinant PspC-SH13 fragment in ELISA, the Factor $\mathrm{H}$-binding derivative PspC-SH12 (30) was used for the competition assays to elucidate the effect of Factor $\mathrm{H}$ and sIgA on vitronectin binding to immobilized PspC. Vitronectin, used at different concentrations $(100 \mu \mathrm{l}$ of $0-40 \mu \mathrm{g} / \mathrm{ml})$, was incubated with a constant amount of Factor $\mathrm{H}(10 \mu \mathrm{g} / \mathrm{ml})$ or sIgA (5 $\mu \mathrm{g} / \mathrm{ml})$, and binding to immobilized PspC-SH12 was measured using goat anti-human Factor $\mathrm{H}$ antibodies (1:2000) and HRPconjugated anti-goat antibodies (1:2500) followed by development with OPD. Bound sIgA was detected with HRP-conjugated anti-IgA antibodies (1:1000). The reaction was developed with OPD.

Surface Plasmon Resonance-The direct protein-protein interactions between vitronectin or vitronectin fragments and $\mathrm{His}_{6}$-tagged PspC protein derivatives were analyzed by SPR using a BIAcoreT100 optical biosensor. Covalent immobilization of proteins on a carboxymethyl dextran (CM5) sensor chip was performed by a standard amine-coupling procedure as described previously (4). Briefly, vitronectin $(5 \mu \mathrm{g} / \mathrm{ml}), \mathrm{Vn}(80-$ 396), Vn(80 -339), or Vn(80 -229) (each $25 \mu \mathrm{g} / \mathrm{ml})$, PspC-SH13 $(30 \mu \mathrm{g} / \mathrm{ml})$, or PspC-SM2 $(50 \mu \mathrm{g} / \mathrm{ml})$ were coupled in $10 \mathrm{~mm}$ sodium acetate, $\mathrm{pH} 4.0$, onto an $N$-hydroxysuccinimide- $(0.05$ M) and $N$-ethyl- $N^{\prime}$ (diethylaminopropyl)carbodiimide (0.2 M)-activated CM5 sensor chip at a flow rate of $10 \mu \mathrm{l} / \mathrm{min}$. The control flow cell was prepared the same way but without injecting the protein. Binding of the analytes was performed in $0.05 \%$ Tween ${ }^{\circledR}$ 20/PBS, pH 7.4, or HNET buffer (50 mM HEPES, 150 mM NaCl, 3 mm EDTA, 0.005\% Tween $\left.{ }^{\circledR} 20, \mathrm{pH} 7.5\right)$ at $25^{\circ} \mathrm{C}$ using a flow rate of 10 or $30 \mu \mathrm{l} / \mathrm{min}$. The affinity surface was regenerated between subsequent sample injections of proteins with $12.5 \mathrm{~mm}$ sodium hydroxide or $2 \mathrm{M} \mathrm{NaCl}$. Each interaction was measured at least three times. The sensorgrams show the response unit values after subtraction of the blank run and value(s) without protein(s) from the corresponding sensorgrams. Binding was analyzed using the BIAcoreT100 Evaluation Software (version 2.0.1.1).
Binding of Bacteria to Immobilized Human Proteins-Microtiter plates (F96, MaxiSorp ${ }^{\mathrm{TM}}$, Nunc-Immuno Module) were coated with $100 \mu \mathrm{l}$ of $10 \mu \mathrm{g} / \mathrm{ml}$ human vitronectin or recombinant vitronectin peptides in $0.1 \mathrm{M}$ sodium carbonate-bicarbonate buffer, $\mathrm{pH} 9.2$, at $4{ }^{\circ} \mathrm{C}$ overnight. The surfaces of the wells were subsequently blocked with $1 \%$ BSA/PBS, pH 7.4, for at least $3 \mathrm{~h}$ at room temperature. Labeling of the bacteria with FITC was performed as described previously (15). Extensively washed FITC-labeled bacteria $\left(100 \mu \mathrm{l}\right.$ of $2 \times 10^{8}$ bacteria) were added to the washed wells and incubated for $1 \mathrm{~h}$ at $37^{\circ} \mathrm{C}$ for binding. Fluorescence was measured at 485/520 nm (excitation/emission) using a multidetection microplate reader (Fluostar Omega, BMG Labtech, Germany). Measurements were done prior to the first washing step (total fluorescence of inoculum) and after each of the four washing steps with $100 \mu \mathrm{l}$ of PBS (fluorescence of bound bacteria).

TCC Deposition Assay-Microtiter plates (F96, Medisorb ${ }^{\mathrm{TM}}$, Nunc-Immuno Module) were coated with PspC-SH12 (100 $\mu \mathrm{l}$ of $5 \mu \mathrm{g} / \mathrm{ml}$ ) overnight at $4{ }^{\circ} \mathrm{C}$. The plates were washed four times with $0.05 \%$ Tween ${ }^{\circledR}$ 20/PBS and blocked for $1 \mathrm{~h}$ at RT with $2 \%$ BSA, $0.05 \%$ Tween ${ }^{\circledR} 20 /$ PBS. After washings, the plates were incubated for $1 \mathrm{~h}$ at RT with vitronectin $(100 \mu \mathrm{l}$ of $0-50$ $\mu \mathrm{g} / \mathrm{ml})$ or Factor $\mathrm{H}(100 \mu \mathrm{l}$ of $0-50 \mu \mathrm{g} / \mathrm{ml})$. Thereafter, the wells were washed and incubated with C5b-6 $(1.5 \mu \mathrm{g} / \mathrm{ml})$ and C7 $(1 \mu \mathrm{g} / \mathrm{ml})$ for $10 \mathrm{~min}$ at RT, and thereafter C8 $(0.2 \mu \mathrm{g} / \mathrm{ml})$ and $C 9(1 \mu \mathrm{g} / \mathrm{ml})$ were added to a total volume of $100 \mu \mathrm{l}$ and incubated for $30 \mathrm{~min}$ at $37^{\circ} \mathrm{C}$. TCC deposition was detected with mouse anti-human C5b-9 mAb (1:1000) and HRP-conjugated swine anti-mouse antibodies (1:2500). The reaction was developed with OPD, and the absorbance was measured at $492 \mathrm{~nm}$.

Statistical Analysis-All data are reported as mean \pm S.D. Results were statistically analyzed using the unpaired twotailed Student's test. A $p$ value of $\leq 0.05$ was considered statistically significant.

\section{RESULTS}

Vitronectin Binds to Intact Pneumococci-S. pneumoniae were previously shown to recruit multimeric vitronectin (4). These results were confirmed by flow cytometric analysis, which revealed a dose-dependent binding of vitronectin to the pneumococcal surface (Fig. $1 A$ and supplemental Fig. S1 $A$ ). To identify pneumococcal surface protein(s) interacting with soluble human vitronectin, pneumococci either lacking sortaseanchored surface proteins due to knock-out of the sortaseencoding gene $s r t A$ or pneumococci deficient in surface expression of functional lipoproteins were examined for vitronectin binding using a flow cytometry-based binding assay. The nonencapsulated pneumococcal strain D39 $\Delta c p s$ and its isogenic mutants D39 $\Delta$ cps $\Delta l g t$, D39 $\Delta c p s \Delta l s p$, or D39 $\Delta$ cps $\Delta s r t A$ showed no differences in their ability to bind soluble vitronectin (Fig. $1 B$ and supplemental Fig. S1B). In contrast, pretreatment of pneumococci with choline chloride, which removes noncovalently bound choline-binding proteins from surface-exposed, phosphorylcholine-decorated teichoic acids (supplemental Fig. S1C), resulted in significantly decreased vitronectin binding (Fig. 1, C and D). Thus, these data suggest that choline-binding proteins contribute to vitronectin binding to the pneumococcal surface. 
A

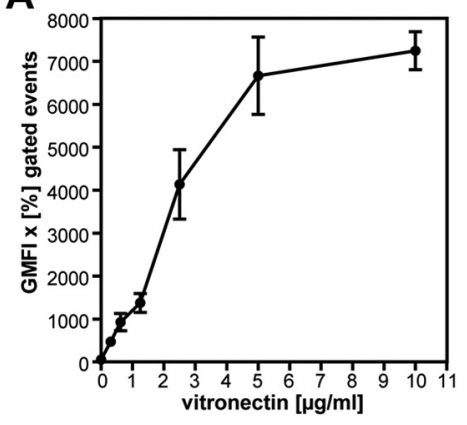

C

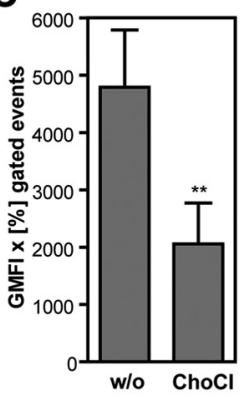

E

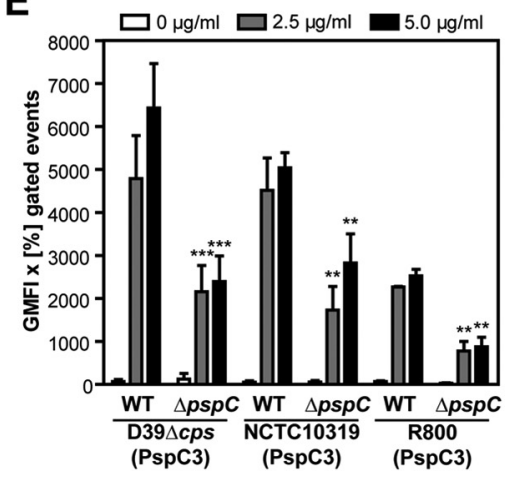

B

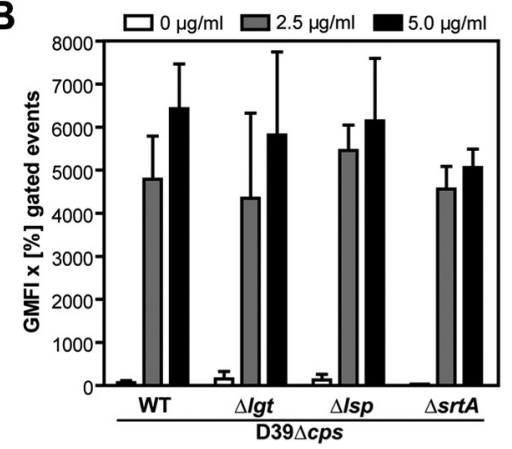

D
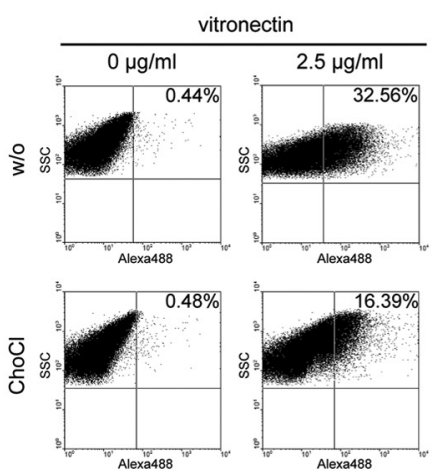

$\mathbf{F}$

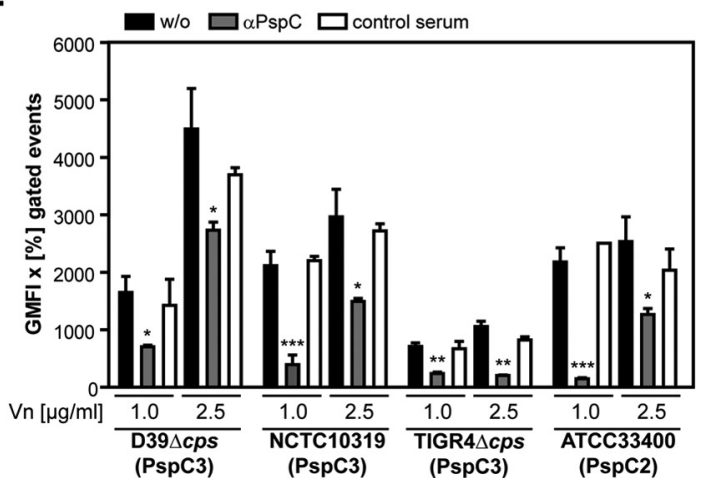

FIGURE 1. Binding of human vitronectin to the pneumococcal surface is mediated by PspC. Recruitment of soluble vitronectin to untreated or pretreated wild-type pneumococci or isogenic mutants $\left(100 \mu \mathrm{l}\right.$ of $1 \times 10^{8}$ bacteria) was determined by flow cytometry. Bound vitronectin was detected using anti-human vitronectin antibodies, followed by an AlexaFluor488-conjugated anti-rabbit lgG. The results were expressed as GMFI $\times$ percentage of AlexaFluor488-labeled and gated bacteria. The mean values of at least three independent experiments are shown with error bars corresponding to S.D. ${ }^{* *}, p \leq 0.01 ;{ }^{* * *}, p \leq 0.001$. Representative dot plots are shown in supplemental Fig. S1.A, dose-dependent binding of soluble vitronectin to S. pneumoniae D39 $\Delta c p s$. B, binding of soluble vitronectin to S. pneumoniae D39 $\Delta$ cps (WT) and its isogenic mutants D39 $\Delta c p s \Delta / g t$, D $39 \Delta c p s \Delta / s p$, or D $39 \Delta c p s \Delta s r t A$. C $-D$, binding of soluble vitronectin to pneumococci devoid of choline-binding proteins. C, S. pneumoniae D39 $\Delta c$ s were incubated with vitronectin $(2.5 \mu \mathrm{g} / \mathrm{ml})$ in the absence $(w / 0)$ or presence of $5 \%$ choline chloride (ChoCl). D, vitronectin bound to the pneumococcal surface in the absence $(\mathrm{w} / \mathrm{o})$ or presence of choline chloride is shown as dot plots of a representative flow cytometric analysis. The control dot plots show the GMFI $\times$ percentage of gated bacteria in the absence of vitronectin but after incubation with the antibodies. E, binding of soluble vitronectin to various pneumococcal strains, represented by low encapsulated (NCTC10319) or nonencapsulated (D39 $\Delta c p s, \mathrm{R} 800)$ pneumococci, and their isogenic $\Delta p s p C$ mutants. The values for the vitronectin binding to D39 $\Delta c p s$ were transferred from $B$. F, inhibition of vitronectin binding to pneumococci expressing different PspC subtypes with a mouse anti-PspC serum or mouse control serum. Vitronectin was used at a concentration of 1 and $2.5 \mu \mathrm{g} / \mathrm{ml}$, respectively.

PspC is a highly abundant, multifunctional choline-binding protein that mediates pneumococcal adhesion to and invasion into host cells but also immune evasion from the host complement. Remarkably, various pneumococcal strains deficient for PspC showed a significantly lower vitronectin binding activity compared with their isogenic wild-type strains as assessed by flow cytometry (Fig. $1 E$ and supplemental Fig. S1D). Similarly, pretreatment of wild-type strains expressing different PspC subtypes with mouse anti-PspC serum significantly decreased vitronectin binding to the pneumococcal cell surface, whereas the control serum showed no effect (Fig. $1 F$ and supplemental Fig. S1, $E-H$ ). These results suggest that PspC is a pneumococcal vitronectin-binding protein.

Analysis of the PspC-Vitronectin Interaction-S. pneumoniae D39 $\Delta$ cps, expressing the PspC3 subtype, efficiently bound vitronectin. Therefore, the recombinant PspC3 derivative SH13 (PspC-SH13) was used to investigate the PspC-vitronectin interaction. To competitively inhibit binding of vitronectin to pneumococci, D39 $\Delta$ cps was incubated with vitronectin in the presence of increasing concentrations of PspC-SH13. Flow cytometric analysis indicated that PspC-SH13 inhibited binding of vitronectin to the pneumococcal cell surface. PspC-SH13 


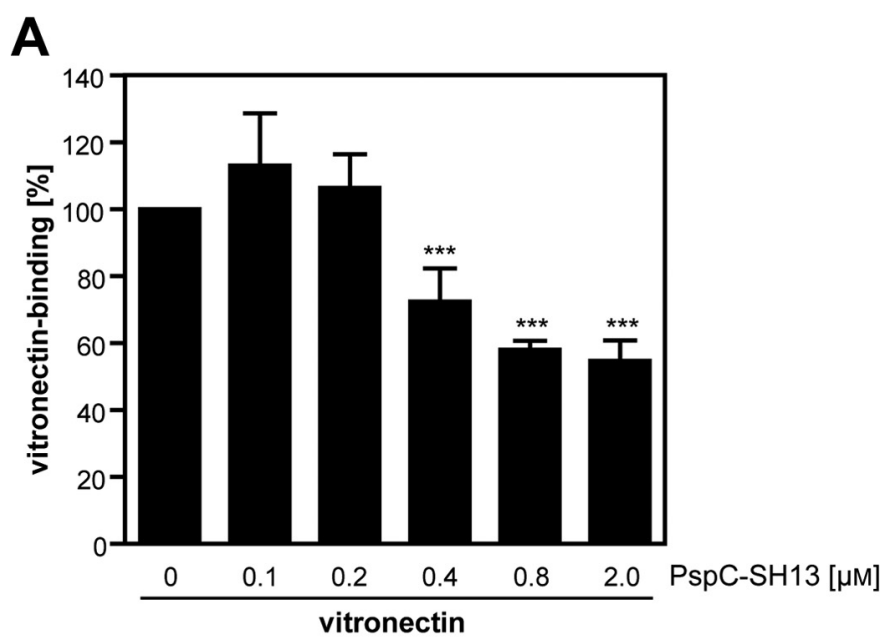

B

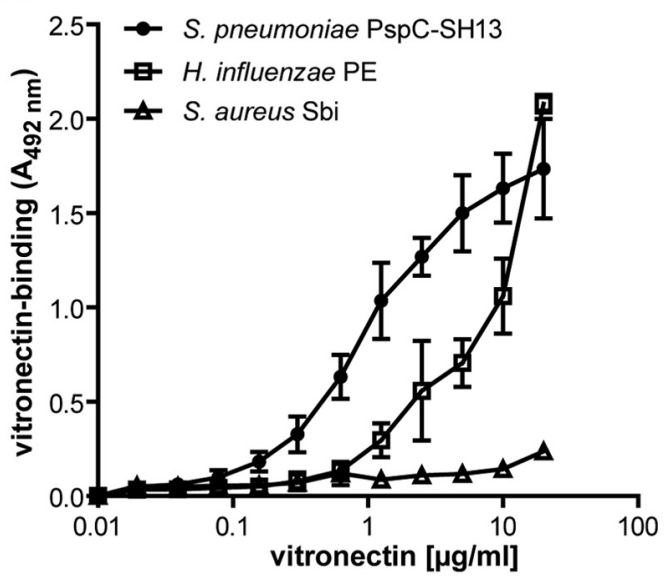

C

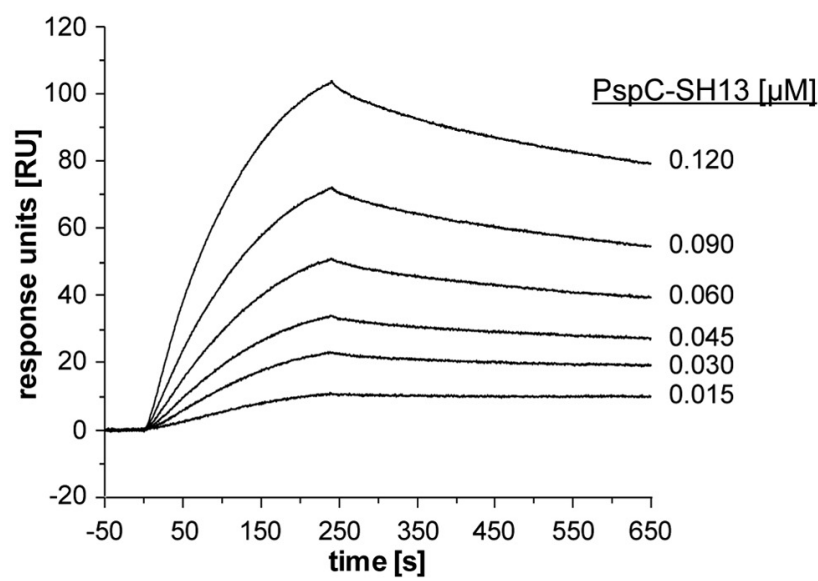

FIGURE 2. Vitronectin binding to PspC subtype 3. $A$, competitive inhibition of vitronectin binding to pneumococci using a derivative of PspC subtype 3.S. pneumoniae D39Acps (100 $\mu$ l of $1 \times 10^{8}$ bacteria) were incubated with vitronectin $(1 \mu \mathrm{g} / \mathrm{ml})$, and binding was competitively inhibited by the addition of increasing concentrations of PspC-SH13 $(0-2 \mu \mathrm{M})$. Binding of vitronectin was determined by flow cytometry (for dot plots of a representative flow cytometric analysis, see supplemental Fig. S2), and data show the percentage of binding relative to vitronectin binding to pneumococci in the absence of protein. The mean values of at least three independent experiments and the S.D. are shown. ${ }^{* * *}, p \leq 0.001 . B$, dose-dependent binding of soluble vitronectin to PspC-SH13. PspC-SH13, S. aureus Sbi, or H. influenzae PE were coated on microtiter plates (each $100 \mu \mathrm{l}$ of $5 \mu \mathrm{g} / \mathrm{ml}$ ) and incubated with increasing concentrations of vitronectin $(0-25 \mu \mathrm{g} / \mathrm{ml}$ in $100 \mu \mathrm{l})$. Bound vitronectin was used at $0.8 \mu \mathrm{M}$ inhibited vitronectin binding to viable pneumococci by $40 \%$ (Fig. $2 A$ and supplemental Fig. S2A). In addition, in an ELISA approach, a dose-dependent binding of vitronectin to immobilized PspC-SH13 was demonstrated. PE, recently identified as a vitronectin-binding adhesin of nontypeable $H$. influenzae $(36,37)$, also bound to vitronectin, whereas Sbi, a Factor $\mathrm{H}$ and C3-binding protein of S. aureus (42), did not interact with vitronectin (Fig. 2B). In a complementary approach, PspC binding to immobilized vitronectin was analyzed by SPR studies. Binding of PspC-SH13 to immobilized vitronectin was dose-dependent and suggests a high binding intensity between adhesin and vitronectin as illustrated by slow dissociation rates of PspC-SH13 (Fig. 2C).

Vitronectin Preferentially Interacts with PspC Derivatives Comprising Two R Domains-To analyze the PspC-vitronectin interaction in more detail and to localize the vitronectin-binding domain in $\mathrm{PspC}$, various $\mathrm{PspC}$ subtypes and derivatives were produced as $\mathrm{His}_{6}{ }_{6}$-tagged proteins in $\mathrm{E}$. coli and employed in binding experiments (Fig. 3A). The ELISA approach showed a dose-dependent vitronectin binding to the immobilized $\mathrm{PspC} 3$ derivative $\mathrm{SH} 13$, whereas lower binding activities were measured for PspC derivatives containing only one or no $\mathrm{R}$ domain (Fig. 3C). SPR analysis was used to verify and compare the binding of the PspC derivatives PspC-SH13, SH2, SH3, and $\mathrm{SM} 2$ to immobilized vitronectin. The $\mathrm{PspC}-\mathrm{SH} 13$ protein comprising the two R domains R1 and R2 showed a high binding activity to vitronectin as indicated by the prominent and fast association and the slow dissociation of the complex upon removal of the analyte. In contrast, $\mathrm{PspC}$ derivatives consisting of only one R domain (PspC-SH2 or SM2) or only the N-terminal part of the mature PspC protein (PspC-SH3) bound with lower intensity to immobilized vitronectin as compared with PspC-SH13 (Fig. $3 D$ and supplemental Fig. S2B-C). Importantly, at a rather low micromolar concentration, PspC-SH13 $(0.09 \mu \mathrm{M})$ showed a remarkably strong binding, whereas the other $\mathrm{His}_{6}$-tagged PspC proteins, even used at higher molar concentrations, interacted with remarkably lower intensities with immobilized vitronectin (Fig. $3 D$ and supplemental Fig. $\mathrm{S} 2 B-C)$.

PspC expressed on the surface of the heterologous expression system $L$. lactis retains its biological activities (41). To assess the differences of PspC subtypes and the role of the number of $\mathrm{R}$ domains on binding of vitronectin, $\mathrm{PspC} 2$ and $\mathrm{PspC} 3$, respectively, were fused to the LPSTG cell wall-anchoring motif of PspC11.4, also known as Hic, and expressed on the surface of L. lactis (Fig. 3B) (43). Binding of the various FITC-labeled recombinant $L$. lactis strains to immobilized vitronectin was examined. Lactococci expressing PspC showed a significantly

detected with anti-human vitronectin antibodies, followed by incubation with HRP-conjugated anti-goat antibodies. 1,2-Phenylenediamine dihydrochloride was used as a substrate, and the absorbance was measured at 492 $\mathrm{nm}$. Results are the mean values \pm S.D. of three independent experiments. $C$, surface plasmon resonance measurements of $\mathrm{PspC}-\mathrm{SH} 13$ binding to immobilized vitronectin. Vitronectin was immobilized on a CM5 biosensor chip to a final rate of 350 response units $(R U)$. PspC-SH13 was used as an analyte at a flow rate of $10 \mu \mathrm{l} / \mathrm{min}$, and the affinity surface was regenerated between subsequent sample injections with $12.5 \mathrm{~mm}$ sodium hydroxide. PspC-SH13 showed a dose-dependent binding to vitronectin expressed in arbitrary response units. A control flow cell was used to subtract nonspecific signals. 
A

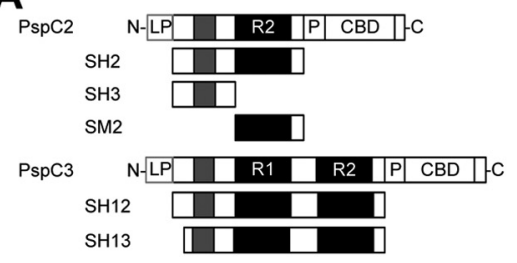

B

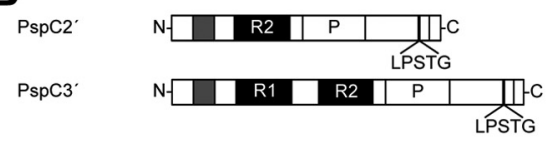

D

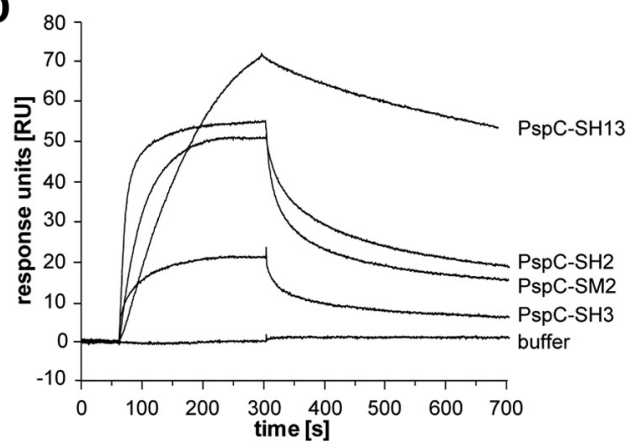

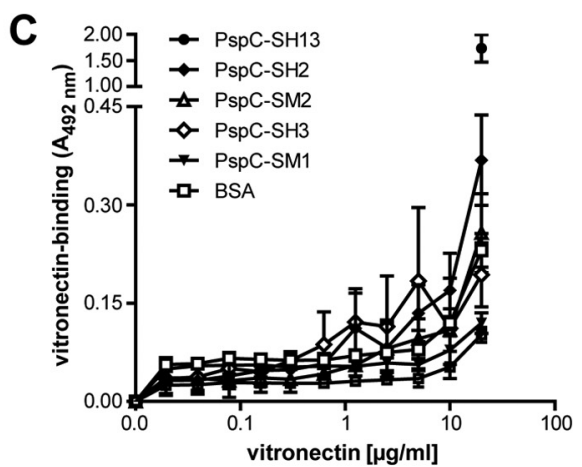

E

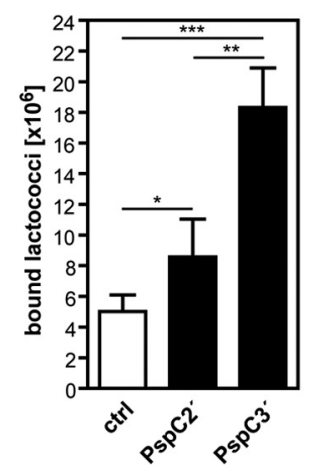

FIGURE 3. Vitronectin preferentially interacts with PspC proteins of subtype 3 . $A$, schematic model of the PspC subtypes 2 and 3 produced as $\mathrm{N}$-terminally $\mathrm{His}_{6}$-tagged protein derivatives in E. coli. B, schematic model of the PspC'-LPSTG fusion proteins for the heterologous expression of PspC on the surface of $L$. lactis. Factor H-binding domain of PspC is shown in dark gray, and the R domains (R1 and R2) of the different PspC variants are depicted in black. Each R domain contains the hexapeptide-binding motif (Y/R)RNYPT for the SC of the plgR and slgA, respectively. $L P$, Leader peptide; $C B D$, choline-binding domain; $P$, proline-rich sequence; $R$, repeat domain. C, binding of vitronectin to immobilized PspC derivatives. PspC subtype 2 (PspC-SH2) or part structures of the mature PspC protein (PspC-SH3 or -SM2) were immobilized on microtiter plates (each $100 \mu \mathrm{l}$ of $5 \mu \mathrm{g} / \mathrm{ml}$ ) and incubated with increasing concentrations of vitronectin $(0-25 \mu \mathrm{g} / \mathrm{ml}$ in $100 \mu \mathrm{l})$. PspC subtype 3 (PspC-SH13) is shown as the control, and the value was transferred from Fig. 2 . Binding of vitronectin was detected as described in Fig. 2. Results are the mean values \pm S.D. of three independent experiments. $D$, binding of PspC derivatives to immobilized vitronectin measured by surface plasmon resonance. PspC-SH13 (representing subtype 3;0.09 $\mu \mathrm{M}$ ), PspC-SH2 (representing subtype 2; $1 \mu \mathrm{M}$ ), the mature $\mathrm{N}$-terminal domain of PspC (PspC-SH3; $4 \mu \mathrm{M}$ ), and one R domain (PspC-SM2; $4 \mu \mathrm{M}$ ), respectively, were used as analytes at a flow rate of $10 \mu \mathrm{l} / \mathrm{min}$, and the affinity surface was regenerated between subsequent sample injections of proteins with $12.5 \mathrm{~mm}$ sodium hydroxide. The amount of PspC binding to immobilized vitronectin is shown in arbitrary response units $(R U)$. E, binding of PspC-expressing lactococci to immobilized vitronectin. PspC expression in L. lactis was induced, and $2 \times 10^{8}$ recombinant lactococci were labeled with FITC. Binding of FITC-labeled bacteria to immobilized vitronectin (50 $\mu \mathrm{l} \mathrm{of} 10 \mu \mathrm{g} / \mathrm{ml}) \mathrm{was} \mathrm{measured} \mathrm{at} 485 / 538 \mathrm{~nm}$ (excitation/emission), and the number of bound bacteria was calculated. The mean values \pm S.D. of at least three independent experiments performed in triplicates are shown. ${ }^{*}, p \leq 0.05 ;{ }^{* *}, p \leq 0.01$; and ${ }^{* * *}, p \leq 0.001$; ctrl, control.

increased binding to immobilized vitronectin as compared with the L. lactis control strain. However, this binding also revealed a significant difference between the two PspC subtypes. Lactococci expressing PspC3 on their surface bound significantly stronger to vitronectin than their PspC2-expressing counterparts (Fig. 3E). These data suggest that the R domains of PspC, which contain the SC-binding motif, are critical for the PspCvitronectin interaction.

Vitronectin Interacts with the SC-binding Region in PspC3To assess the important role of the $\mathrm{R}$ domains of PspC3 for the interaction with vitronectin, the effect of the two other PspC ligands Factor $\mathrm{H}$ and sIgA on vitronectin binding to viable pneumococci was assayed by flow cytometry. In this approach, Factor $\mathrm{H}$, which binds to a region $\mathrm{N}$-terminal to the $\mathrm{R}$ domain(s) in the PspC protein, did not inhibit binding of biotin-labeled vitronectin to pneumococci (Fig. $4 A$ and supplemental Fig. S3A). In contrast, sIgA, which binds to a conserved hexapeptide motif within the $\mathrm{R}$ domain, dose-dependently reduced the recruitment of vitronectin to the bacterial surface. sIgA used at a concentration of $125 \mu \mathrm{g} / \mathrm{ml}$ inhibited vitronectin binding to pneumococci by $\sim 50 \%$ (Fig. $4 B$ and supplemental Fig. S3B). To analyze whether Factor $\mathrm{H}$ and vitronectin bind concurrently to PspC, binding of vitronectin to immobilized PspC-SH12 in the presence of Factor H was investigated. Factor $\mathrm{H}$ did not inhibit the dose-dependent binding of vitronectin to the immobilized PspC3 derivative SH12 (Fig. 4C). In addition, Factor $\mathrm{H}$ bound dose-dependently to PspCSH12 in the presence of vitronectin (data not shown). In contrast, binding of sIgA to immobilized PspC-SH12 was significantly reduced upon addition of increasing concentrations of vitronectin (Fig. 4D). Similarly, binding of vitronectin was diminished at increasing concentrations of sIgA and a constant amount of vitronectin (data not shown). These results demonstrate that $\operatorname{sIgA}$, but not Factor $\mathrm{H}$, competes with vitronectin for binding to PspC, thus suggesting that the R domain(s) of PspC are important for the interaction of pneumococci with human vitronectin.

The C-terminal Heparin-binding Domain of Vitronectin Is Essential for the Interaction with PspC3-To characterize the biochemical features of the PspC interaction with vitronectin, binding of vitronectin to immobilized PspC-SH13 was analyzed in the presence of $\mathrm{NaCl}$. Binding of vitronectin to PspC-SH13 
A

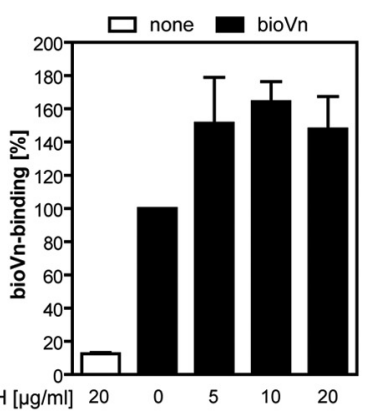

C

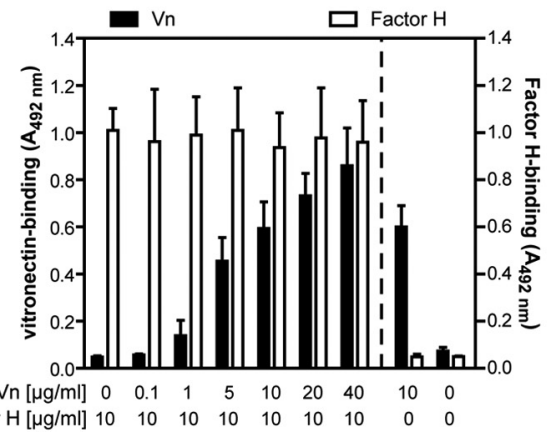

B

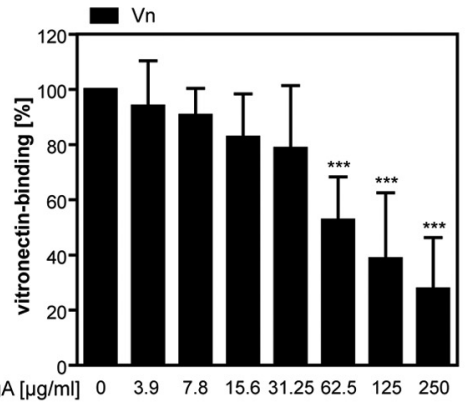

D

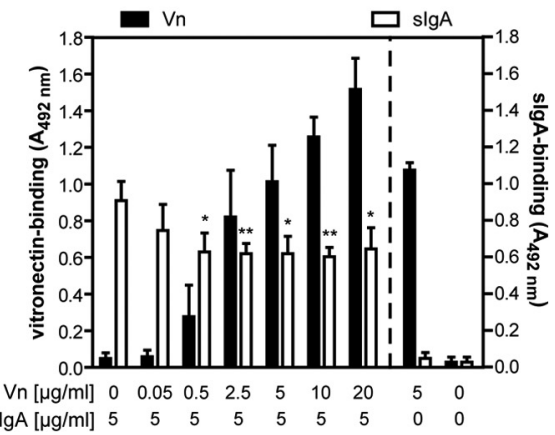

FIGURE 4. Vitronectin and slgA compete for binding to pneumococci and PspC. A, Factor H does not interfere with vitronectin binding to viable pneumococci. S. pneumoniae D39 $\Delta$ cps (100 $\mu \mathrm{l}$ of $1 \times 10^{8}$ bacteria) were incubated with $1 \mu \mathrm{g} / \mathrm{ml}$ biotinylated vitronectin (bio Vn) in the presence of increasing concentrations of Factor $\mathrm{H}(0-20 \mu \mathrm{g} / \mathrm{ml})$. Bound vitronectin was detected using Alexa488-conjugated streptavidin, and binding was measured by flow cytometry. Binding of vitronectin in the absence of Factor $\mathrm{H}$ was defined as $100 \%$. The mean values of at least three independent experiments and the S.D. are shown. $B$, secretory IgA inhibits vitronectin binding to the pneumococcal surface. S. pneumoniae D39 $\Delta$ cps $\left(100 \mu\right.$ l of $1 \times 10^{8}$ bacteria) were incubated with vitronectin $(1 \mu \mathrm{g} / \mathrm{ml})$ in the presence of slgA $(0-250 \mu \mathrm{g} / \mathrm{ml})$. Binding of vitronectin was measured by flow cytometry as described in Fig. 1, and vitronectin binding to pneumococci in the absence of slgA was defined as $100 \%$. The mean values \pm S.D. of at least three independent experiments are shown. ${ }^{* * *}, p \leq$ 0.001. $A$ and $B$, representative dot plots are shown in supplemental Fig. S3. C, Factor H does not compete with vitronectin for binding to immobilized PspC. In a total volume of $100 \mu \mathrm{l}$, Factor $\mathrm{H}(10 \mu \mathrm{g} / \mathrm{ml})$ was incubated with increasing concentrations of vitronectin $(0-40 \mu \mathrm{g} / \mathrm{ml})$, and binding of vitronectin or Factor $\mathrm{H}$ to immobilized PspC subtype $3(100 \mu \mathrm{l}$ of $5 \mu \mathrm{g} / \mathrm{ml})$ was measured. Results are shown as the mean values \pm S.D. of at least three independent experiments. $D$, binding of slgA to immobilized PspC is inhibited by vitronectin. In a total volume of $100 \mu \mathrm{l}$, increasing amounts of vitronectin $(0-20 \mu \mathrm{g} / \mathrm{ml}) \mathrm{were}$ employed to inhibit binding of secretory $\lg A(5 \mu \mathrm{g} / \mathrm{ml})$ to immobilized PspC subtype $3(100 \mu \mathrm{l}$ of $5 \mu \mathrm{g} / \mathrm{ml})$. Binding of vitronectin or slgA was detected using specific antisera. The graph shows the mean values \pm S.D. of at least three independent experiments. ${ }^{*}, p \leq 0.05 ;{ }^{*}, p \leq 0.01$.

was salt-sensitive. Sodium chloride at $250 \mathrm{~mm}$ decreased vitronectin binding by $20 \%$, and in the presence of $1 \mathrm{M} \mathrm{NaCl}$, the interaction was inhibited by $\sim 70 \%$ (Fig. $5 A$ ). Heparin inhibits the vitronectin-mediated adherence of pneumococci to epithelial cells (4). To examine whether the heparin-binding site(s) of vitronectin are relevant for the interaction with PspC, the effect of heparin, heparan sulfate, and chondroitin sulfate A on vitronectin binding to immobilized PspC-SH13 was tested. Indeed, all three glucosaminoglycans inhibited the binding of vitronectin to PspC (Fig. 5, $B-D$ ) in a dose-dependent manner. Heparin at a concentration of $1 \mu \mathrm{g} / \mathrm{ml}$ reduced vitronectin binding to immobilized PspC-SH13 by $80 \%$ (Fig. $5 B$ ). Vitronectin contains three heparin-binding domains named HBD1-3, and various bacteria recognize at least one of them to evade the host's immune system or to indirectly link themselves to integrins for colonization and internalization (39). To localize which of the three HBDs in vitronectin is relevant for contacting PspC and to narrow down its binding motif, a series of recombinant fragments spanning amino acid residues 80-396 of the vitronectin molecule (Fig. $5 E$ ) was examined for binding to immobilized PspC-SH13. The truncated vitronectin fragments $\mathrm{Vn}(80-396), \operatorname{Vn}(80-379), \operatorname{Vn}(80-373)$, and $\mathrm{Vn}(80-363)$ showed similar PspC binding activities. In contrast, $\mathrm{Vn}(80-$ 353) and further $\mathrm{C}$-terminally truncated vitronectin fragments lacking the $\mathrm{C}$-terminal heparin-binding domain (HBD3) did not bind to immobilized PspC-SH13 (Fig. 5F and supplemental Fig. S4A). In addition, binding of selected recombinant vitronectin fragments to S. pneumoniae D39 $\Delta c p s$ was analyzed by flow cytometry. The vitronectin fragments $\operatorname{Vn}(80-396)$ and $\operatorname{Vn}(80-363)$ bound to viable pneumococci, and their binding was comparable with the full-length vitronectin. In contrast, vitronectin fragments lacking the C-terminal HBD3 (i.e. $\mathrm{Vn}(80-353), \mathrm{Vn}(80-339)$, and $\mathrm{Vn}(80-229))$ bound to an extent of only $5-10 \%$ to the pneumococcal cell surface (Fig. $5 G$ and supplemental Fig. S4B).

A Sequence N-terminal to the HBD3 of Immobilized Vitronectin Provides an Additional Structural Binding Site for PspC3Pneumococci preferentially interact with host cell-bound vitronectin (4). Therefore, binding of FITC-labeled bacteria to immobilized vitronectin fragments was assayed. FITC-labeled D39 $\Delta$ cps and PspC3-expressing recombinant L. lactis showed binding activity to $\mathrm{Vn}(80-396), \mathrm{Vn}(80-379), \mathrm{Vn}(80-373)$, $\mathrm{Vn}(80-363)$, as well as to $\mathrm{Vn}(80-353)$ and $\mathrm{Vn}(80-339)$. A further $\mathrm{C}$-terminal truncation, represented by the vitronectin fragment $\mathrm{Vn}(80-229)$, was necessary to substantially reduce the interaction of PspC-expressing pneumococci and lactococci with immobilized vitronectin (Fig. 6, $A$ and $B$ ). In surface plasmon resonance measurements, $\mathrm{PspC}-\mathrm{SH} 13$ showed similar binding activities to the immobilized vitronectin fragments $\mathrm{Vn}(80-396)$ and $\mathrm{Vn}(80-339)$, but significantly reduced binding intensities to immobilized $\operatorname{Vn}(80-229)$ (supplemental Fig. S5). 
A

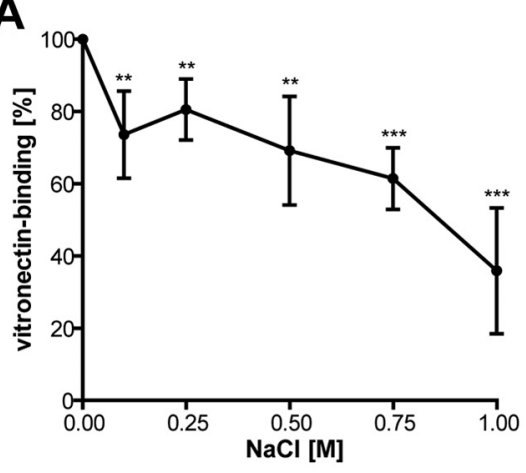

C

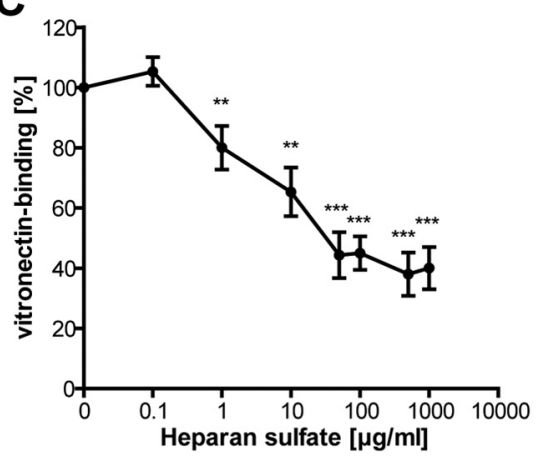

E

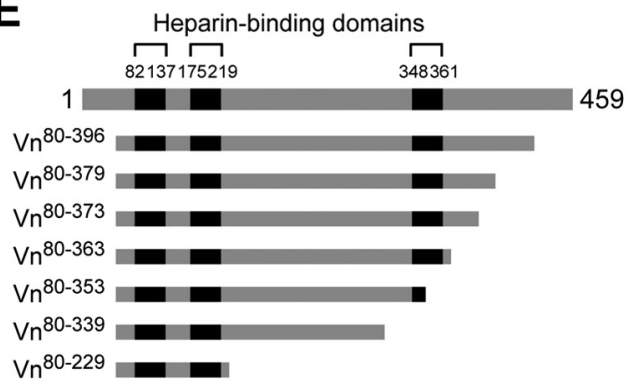

G

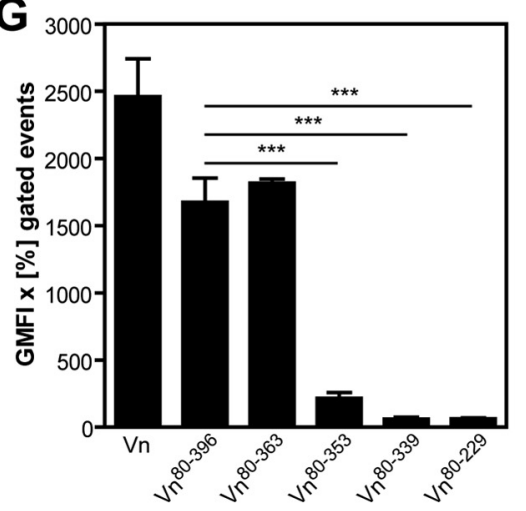

B

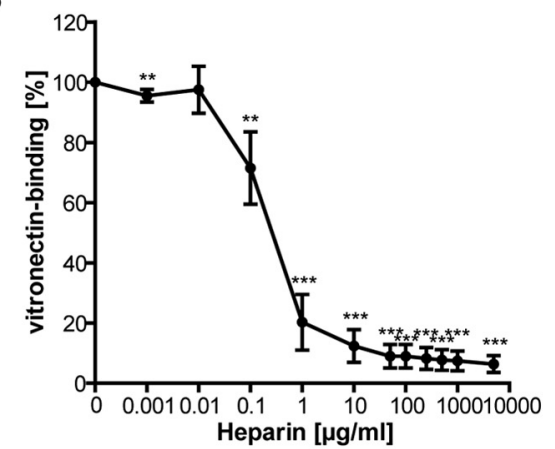

D

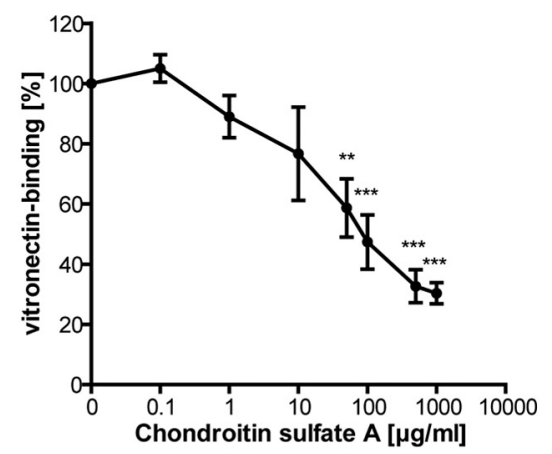

$\mathbf{F}$

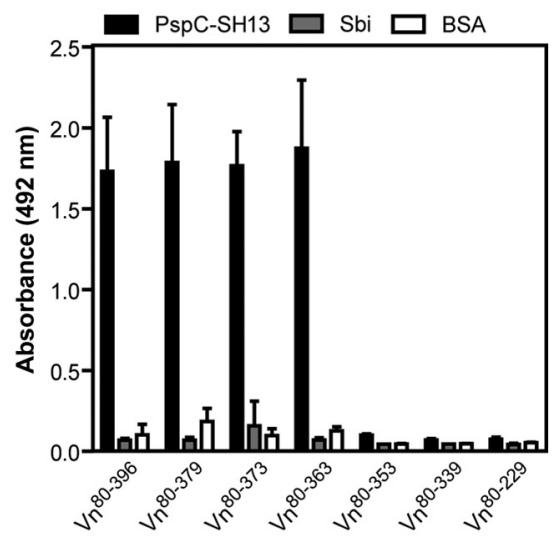

FIGURE 5. C-terminal heparin-binding domain of vitronectin mediates binding to pneumococci and PspC. $A-D$, binding of vitronectin to PspC is chargedependent and inhibited by heparin. PspC-SH13 was coated on microtiter plates $(100 \mu \mathrm{l}$ of $5 \mu \mathrm{g} / \mathrm{ml})$, and binding of vitronectin $(100 \mu \mathrm{l}$ of $5 \mu \mathrm{g} / \mathrm{ml})$ was measured in the presence of increasing concentrations of $\mathrm{NaCl}(0-1 \mathrm{M})(A)$, heparin $(0-5000 \mu \mathrm{g} / \mathrm{ml})(B)$, heparan sulfate $(0-1000 \mu \mathrm{g} / \mathrm{ml})(C)$, or chondroitin sulfate $A(0-1000 \mu \mathrm{g} / \mathrm{ml})(D)$. The three heparin-binding domains are depicted in black. $E$, schematic models of the recombinant vitronectin derivatives produced in HEK293T cells. The three heparin-binding domains are depicted in black. F, binding of soluble vitronectin to PspC requires the C-terminal HBD of vitronectin. Binding of soluble recombinant vitronectin peptides (each $100 \mu \mathrm{l} \mathrm{of} 5 \mu \mathrm{g} / \mathrm{ml}$ ) to immobilized PspC-SH13, Sbi, or BSA (each $100 \mu \mathrm{l}$ of $5 \mu \mathrm{g} / \mathrm{ml}$ ) was determined by ELISA. The mean values \pm S.D. of at least three independent experiments are shown in $A, B$, and $D$, respectively. ${ }^{* *}, p \leq 0.01$; ${ }^{* * *}, p \leq 0.001$. $G$, C-terminal HBD of vitronectin is essential for binding of soluble vitronectin to pneumococci. S. pneumoniae D39 $\Delta$ cps $\left(100 \mu\right.$ l of $1 \times 10^{8}$ bacteria) were incubated with soluble vitronectin $(1 \mu \mathrm{g} / \mathrm{ml}$ ) or recombinant C-terminally truncated vitronectin fragments (each $5 \mu \mathrm{g} / \mathrm{ml}$ ). Bound vitronectin was detected as described in Fig. 1 and measured by flow cytometry (for dot plots of a representative flow cytometric analysis, see supplemental Fig. S4). The results were expressed as GMFI multiplied with the percentage of fluorescent and gated bacteria. Results are shown as the mean values $\pm S$.D. of at least three independent experiments. ${ }^{* *}, p \leq 0.01 ;{ }^{* * *}, p \leq 0.001$. 

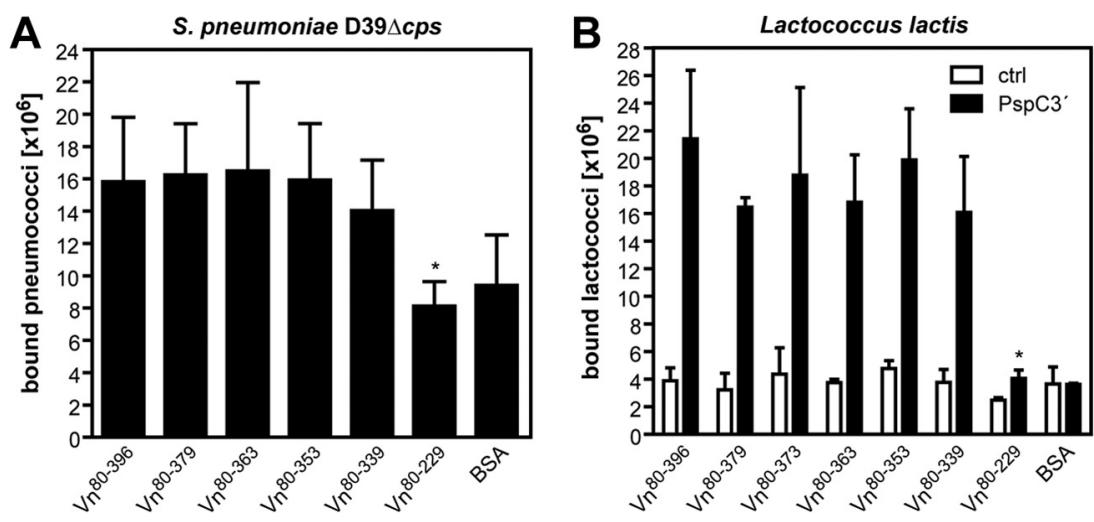

FIGURE 6. Immobilization of vitronectin exposes an additional PspC-binding site in a region $\mathbf{N}$-terminal to the HBD3. Binding of $2 \times 10^{8} \mathrm{FITC}$-labeled S. pneumoniae D39 $\Delta$ cps $(A)$ or recombinant L. lactis $(B)$ to immobilized recombinant vitronectin peptides (each $50 \mu \mathrm{l}$ of $5 \mu \mathrm{g} / \mathrm{ml}$ ) was measured at $485 / 538 \mathrm{~nm}$ (excitation/emission). BSA was used as a control protein. The number of bound bacteria was calculated, and the graphs show the mean values \pm S.D. of at least three independent experiments performed in duplicates. ${ }^{*}, p \leq 0.05$.

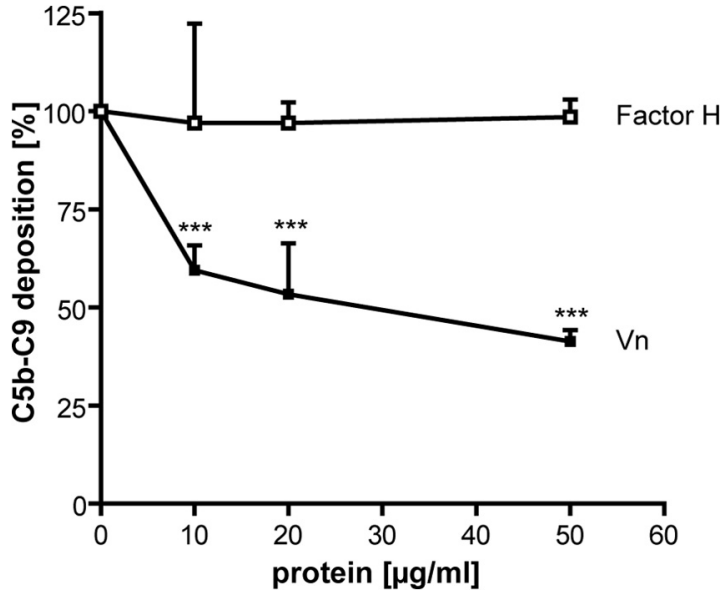

FIGURE 7. Vitronectin bound to PspC3 is functionally active and inhibits TCC deposition. Vitronectin or Factor $\mathrm{H}$ was incubated at increasing concentrations $(0-50 \mu \mathrm{g} / \mathrm{ml}$ in $100 \mu \mathrm{l})$ with immobilized PspC-SH12 $(100 \mu \mathrm{l}$ of 5 $\mu \mathrm{g} / \mathrm{ml})$. After incubation with C5b-6 and C7, C8 and C9 were added to a total volume of $100 \mu \mathrm{l}$, and TCC deposition was detected using anti-human C5b-9 monoclonal antibodies followed by HRP-conjugated anti-mouse lgG. Results are shown as the mean values \pm S.D. of at least three independent experiments. ${ }^{* *}, p \leq 0.001$

Vitronectin Bound to PspC3 Is Functionally Active and Inhibits TCC Deposition-Vitronectin controls the terminal complement pathway by binding the C5b-7 complex and thereby blocks the assembly and deposition of the TCC $(32,33,39)$. Vitronectin bound to PspC-SH13 inhibited TCC deposition in a dose-dependent manner. Vitronectin used at $50 \mu \mathrm{g} / \mathrm{ml}$ reduced TCC deposition by $\sim 60 \%$ (Fig. 7). In contrast, the C3 convertase inhibitor Factor $\mathrm{H}$ showed no effect (Fig. 7). Thus, vitronectin, bound to $\mathrm{PspC}$, maintains its central regulatory function and controls complement at the level of the terminal pathway.

\section{DISCUSSION}

S. pneumoniae utilize human multimeric vitronectin to adhere and invade host cells via the integrin route. Pneumococci exploit vitronectin as a molecular bridge to access $\alpha_{\mathrm{v}} \beta_{3}$ integrin receptors, which results in an activation of the PI3KAkt signaling pathway via the integrin-linked kinase, induces rearrangements of the host cell actin cytoskeleton, and enhances pneumococcal internalization. The interaction between pneumococci and vitronectin is impaired after proteolytic treatment of the bacterial surface suggesting a proteinaceous nature of the vitronectin-binding factor (4). In this study, we showed that sortase- or lipid-anchored proteins are likely not involved in vitronectin binding to the pneumococcal surface (Fig. $1 B$ and supplemental Fig. S1B). However, removal of choline-binding proteins from the pneumococcal surface resulted in a significant decrease in vitronectin binding (Fig. 1, $C$ and $D$, and supplemental Fig. $\mathrm{S} 1 C$ ). PspC is a highly abundant choline-binding surface protein of pneumococci, and $p s p C$-deficient mutants showed a significantly reduced binding of vitronectin (Fig. $1 E$ and supplemental Fig. S1D). In addition, pretreatment of pneumococcal strains expressing different PspC subtypes with anti-PspC antiserum diminished vitronectin binding (Fig. $1 E$ and supplemental Fig. S1E-H). These data suggest a role of PspC for the interaction of pneumococci with vitronectin. Classical PspC proteins consist of an $\mathrm{N}$-terminal Factor $\mathrm{H}$-binding region followed by either one or two $\alpha$-helical SC-binding repeat domains (R1 and R2) connected by a flexible short random coil, a proline-rich region, and the choline-binding domain at the $\mathrm{C}$ terminus. The PspC2 subtype present in $S$. pneumoniae ATCC33400 contains only one R domain, whereas PspC3 produced by S. pneumoniae D39 and TIGR4, respectively, contains two R domains (21-23). Factor H did not compete with vitronectin for binding to PspC displayed on the pneumococcal surface or to immobilized purified PspC protein (Fig. $4 A$ and supplemental Fig. S3A). In contrast, sIgA inhibited the interaction of vitronectin to pneumococcal surface-exposed PspC by $\sim 70 \%$ as measured by flow cytometry (Fig. $4 B$ and supplemental Fig. S3B). Binding of sIgA to immobilized recombinant $\mathrm{PspC}$ protein was also significantly inhibited by vitronectin; however, the efficiency was less pronounced under these conditions (Fig. 4D). sIgA has a high affinity (in the nanomolar range) to its hexapeptide-binding motif in the mature PspC molecule $(24,25)$, whereas the affinity of vitronectin to its still undefined binding epitope in PspC appears to be in the micromolar range, when calculating the dissociation constant using the 1:1 Langmuir binding model of the BIAEvaluation software (data not shown). In addition, these inhibition data suggest that sIgA and vitronectin do not recognize identical 


\section{Pneumococcal PspC Binds Vitronectin}

sequence motifs in the $\mathrm{R}$ domain(s), although the $\mathrm{R}$ domain(s) of PspC are essential for binding of both human proteins.

The PspC3 derivative PspC-SH13 efficiently bound vitronectin compared with PspC peptides comprising one $\mathrm{R}$ domain or only the Factor $\mathrm{H}$-binding site (Figs. 2 and 3 and supplemental Fig. S2). These results suggested that two interconnected $\mathrm{R}$ domains are essential for efficient vitronectin binding. For ECM-recognizing adhesins of staphylococci and enterococci, three distinct binding mechanisms are proposed, i.e. the "tandem $\beta$-zipper," the "dock, lock, and latch," and the "collagen hug" models. The two latter are characterized by two subdomains cooperating to capture the ligand molecule and a third subdomain securing the binding (44). These models, however, rely on the presence of Ig-like folds formed by antiparallel $\beta$-strands and hydrophobic interactions between adhesin and ligand. Recently, PavB of S. pneumoniae was shown to bind the adhesive glycoprotein fibronectin via its repetitive sequences (referred to as streptococcal surface repeats). Although one streptococcal surface repeat domain is sufficient for binding to fibronectin, the efficiency of the PavB-fibronectin interaction increases with the number of streptococcal surface repeats (45). These data are in agreement with the assumption that the number of repeats influences protein structure, activity, and function (46). Biophysical and structural data of PspC in complex with vitronectin are not available, which would provide comprehensive insights into the binding mechanism of the pneumococcal adhesin to the multifunctional human glycoprotein. PspC consists of charged "hot spots," which may serve as binding sites for vitronectin as follows: (i) a highly charged region containing the SC-binding motif, and (ii) the R domain-connecting random coil with a high abundance of charged residues $(21,22)$. Charge plays a fundamental role in binding of vitronectin to PspC (Fig. 5A). Vitronectin contains three HBDs that are located at residues $82-137,175-219$, and 348-361 (Fig. 5E) (39). The negatively charged glycosaminoglycans heparin, heparan sulfate, and chondroitin sulfate A (Fig. 5, $B-D$ ), but not the positively charged $\epsilon$-aminocaproic acid and poly-L-lysine, inhibited PspC binding to the C-terminal heparin-binding domain of vitronectin (data not shown). This suggests that the positively charged lysine residues within $\mathrm{PspC}$ are not involved in binding of vitronectin, whereas negatively charged (acidic) amino acid residues within $\mathrm{PspC}$ play a major role in this protein-protein interaction.

To localize the PspC-binding domain in vitronectin, recombinant vitronectin fragments were analyzed for their ability to bind PspC. Vitronectin fragments lacking the C-terminal heparin-binding domain did not bind to immobilized PspC nor to the bacterial surface (Fig. 5, F and G, and supplemental Fig. S4). These data indicate that $\mathrm{PspC}$ recognizes the C-terminal HBD and thus resembles the binding features observed for proteins of other human pathogens, e.g. H. influenzae PE, Moraxella catarrhalis UspA2 and UspA2 variant proteins (UspA2V), and Neisseria meningitidis Opc $(38,39,47)$. Furthermore, PspC seems to interact with a region between HBD2 and HBD3 (residues 229-339) when vitronectin is immobilized on inert or biosensor surfaces (Fig. 6, $A$ and $B$, and supplemental Fig. S5). These differences in binding may be due to different conformations assumed by soluble versus host cell-bound vitronectin.
Bacteria interacting with host ECM or serum proteins are often able to discriminate between particular states, i.e. soluble, immobilized, monomeric, or oligomeric structures, of a certain host protein. For example, PavA and PavB of S. pneumoniae preferentially recognize immobilized versus soluble fibronectin $(14,45)$. Similarly, the oral streptococci Streptococcus mutans, Streptococcus sanguis, and Streptococcus gordonii and viruses such as HIV adhere efficiently to a multimeric form of fibronectin that closely resembles in vivo matrix-associated fibronectin, but not the soluble form (48-51).

Recruitment of human serum proteins to the bacterial surface allows complement control. Gram-negative pathogenic bacteria recruit plasma vitronectin to prevent the formation and deposition of the TCC and subsequent bacterial lysis. Recently, $H$. influenzae PE was shown to exclusively interact with the $\mathrm{C}$-terminal heparin-binding domain of vitronectin to evade innate defense mechanisms (36-38). Encapsulated pneumococci are usually serum-resistant (52-54). However, the intimate contact of pneumococci with human host cells is associated with a loss of capsule polysaccharides, which renders these bacteria susceptible to innate immune responses (55-57). Therefore, we verified the inhibition of TCC deposition by vitronectin bound to PspC. Indeed, PspC-bound vitronectin inhibited the deposition of the TCC (Fig. 7) demonstrating that vitronectin is functionally active and may protect pneumococci against the attack of the complement system.

In conclusion, this study suggests that the multifunctional protein PspC plays a crucial role in binding the human adhesive glycoprotein vitronectin, besides being highly important for pneumococcal adhesion to host cells via the polymeric Ig receptor and interaction with proteins like secretory IgA and Factor $\mathrm{H}$. Furthermore, the data indicate that two $\mathrm{R}$ domains within PspC, represented by PspC subtype 3, are required for the efficient interaction of S. pneumoniae with vitronectin. Although PspC exclusively binds to the C-terminal heparin-binding domain of soluble vitronectin, it appears that a region directly $\mathrm{N}$-terminal to the HBD3 of immobilized vitronectin, which mimics host cell-bound vitronectin in vitro, provides a further recognition site for PspC.

\section{REFERENCES}

1. Cartwright, K. (2002) Pneumococcal disease in Western Europe: burden of disease, antibiotic resistance, and management. Eur. J. Pediatr. 161, $188-195$

2. Agarwal, V., Asmat, T. M., Luo, S., Jensch, I., Zipfel, P. F., and Hammerschmidt, S. (2010) Complement regulator Factor H mediates a two-step uptake of Streptococcus pneumoniae by human cells. J. Biol. Chem. 285, 23486-23495

3. Anderton, J. M., Rajam, G., Romero-Steiner, S., Summer, S., Kowalczyk, A. P., Carlone, G. M., Sampson, J. S., and Ades, E. W. (2007) E-cadherin is a receptor for the common protein pneumococcal surface adhesin A (PsaA) of Streptococcus pneumoniae. Microb. Pathog. 42, 225-236

4. Bergmann, S., Lang, A., Rohde, M., Agarwal, V., Rennemeier, C., Grashoff, C., Preissner, K. T., and Hammerschmidt, S. (2009) Integrin-linked kinase is required for vitronectin-mediated internalization of Streptococcus pneumoniae by host cells. J. Cell Sci. 122, 256-267

5. Romero-Steiner, S., Caba, J., Rajam, G., Langley, T., Floyd, A., Johnson, S. E., Sampson, J. S., Carlone, G. M., and Ades, E. (2006) Adherence of recombinant pneumococcal surface adhesin $\mathrm{A}$ ( $\mathrm{rPsaA}$ )-coated particles to human nasopharyngeal epithelial cells for the evaluation of anti-PsaA functional antibodies. Vaccine 24, 3224-3231 
6. Rose, L., Shivshankar, P., Hinojosa, E., Rodriguez, A., Sanchez, C. J., and Orihuela, C. J. (2008) Antibodies against PsrP, a novel Streptococcus pneumoniae adhesin, block adhesion and protect mice against pneumococcal challenge. J. Infect. Dis. 198, 375-383

7. Shivshankar, P., Sanchez, C., Rose, L. F., and Orihuela, C. J. (2009) The Streptococcus pneumoniae adhesin PsrP binds to Keratin 10 on lung cells. Mol. Microbiol. 73, 663-679

8. Voss, S., Gámez, G., and Hammerschmidt, S. (2012) Impact of pneumococcal microbial surface components recognizing adhesive matrix molecules on colonization. Mol. Oral Microbiol. 27, 246-256

9. Attali, C., Frolet, C., Durmort, C., Offant, J., Vernet, T., and Di Guilmi, A. M. (2008) Streptococcus pneumoniae choline-binding protein E interaction with plasminogen/plasmin stimulates migration across the extracellular matrix. Infect. Immun. 76, 466-476

10. Bergmann, S., Rohde, M., Chhatwal, G. S., and Hammerschmidt, S. (2001) $\alpha$-Enolase of Streptococcus pneumoniae is a plasmin(ogen)-binding protein displayed on the bacterial cell surface. Mol. Microbiol. 40, 1273-1287

11. Bergmann, S., Rohde, M., and Hammerschmidt, S. (2004) Glyceraldehyde-3-phosphate dehydrogenase of Streptococcus pneumoniae is a surface-displayed plasminogen-binding protein. Infect. Immun. 72, $2416-2419$

12. Hilleringmann, M., Giusti, F., Baudner, B. C., Masignani, V., Covacci, A., Rappuoli, R., Barocchi, M. A., and Ferlenghi, I. (2008) Pneumococcal pili are composed of protofilaments exposing adhesive clusters of RrgA. PLoS Pathog. 4, e1000026

13. Papasergi, S., Garibaldi, M., Tuscano, G., Signorino, G., Ricci, S., Peppoloni, S., Pernice, I., Lo Passo, C., Teti, G., Felici, F., and Beninati, C. (2010) Plasminogen- and fibronectin-binding protein $\mathrm{B}$ is involved in the adherence of Streptococcus pneumoniae to human epithelial cells. J. Biol. Chem. 285, 7517-7524

14. Pracht, D., Elm, C., Gerber, J., Bergmann, S., Rohde, M., Seiler, M., Kim, K. S., Jenkinson, H. F., Nau, R., and Hammerschmidt, S. (2005) PavA of Streptococcus pneumoniae modulates adherence, invasion, and meningeal inflammation. Infect. Immun. 73, 2680-2689

15. Rennemeier, C., Hammerschmidt, S., Niemann, S., Inamura, S., Zähringer, U., and Kehrel, B. E. (2007) Thrombospondin-1 promotes cellular adherence of Gram-positive pathogens via recognition of peptidoglycan. FASEB J. 21, 3118-3132

16. Yamaguchi, M., Terao, Y., Mori, Y., Hamada, S., and Kawabata, S. (2008) $\mathrm{PfbA}$, a novel plasmin- and fibronectin-binding protein of Streptococcus pneumoniae, contributes to fibronectin-dependent adhesion and antiphagocytosis. J. Biol. Chem. 283, 36272-36279

17. Gamez, G., and Hammerschmidt, S. (2012) Combat pneumococcal infections: adhesins as candidates for protein-based vaccine development. Curr. Drug Targets 13, 323-337

18. Bagnoli, F., Moschioni, M., Donati, C., Dimitrovska, V., Ferlenghi, I., Facciotti, C., Muzzi, A., Giusti, F., Emolo, C., Sinisi, A., Hilleringmann, M., Pansegrau, W., Censini, S., Rappuoli, R., Covacci, A., Masignani, V., and Barocchi, M. A. (2008) A second pilus type in Streptococcus pneumoniae is prevalent in emerging serotypes and mediates adhesion to host cells. J. Bacteriol. 190, 5480-5492

19. Barocchi, M. A., Ries, J., Zogaj, X., Hemsley, C., Albiger, B., Kanth, A., Dahlberg, S., Fernebro, J., Moschioni, M., Masignani, V., Hultenby, K., Taddei, A. R., Beiter, K., Wartha, F., von Euler, A., Covacci, A., Holden, D. W., Normark, S., Rappuoli, R., and Henriques-Normark, B. (2006) A pneumococcal pilus influences virulence and host inflammatory responses. Proc. Natl. Acad. Sci. U.S.A. 103, 2857-2862

20. Nelson, A. L., Ries, J., Bagnoli, F., Dahlberg, S., Falker, S., Rounioja, S., Tschop, J., Morfeldt, E., Ferlenghi, I., Hilleringmann, M., Holden, D. W., Rappuoli, R., Normark, S., Barocchi, M. A., and Henriques-Normark, B. (2007) RrgA is a pilus-associated adhesin in Streptococcus pneumoniae. Mol. Microbiol. 66, 329-340

21. Brooks-Walter, A., Briles, D. E., and Hollingshead, S. K. (1999) The $p s p C$ gene of Streptococcus pneumoniae encodes a polymorphic protein, PspC, which elicits cross-reactive antibodies to PspA and provides immunity to pneumococcal bacteremia. Infect. Immun. 67, 6533-6542

22. Iannelli, F., Oggioni, M. R., and Pozzi, G. (2002) Allelic variation in the highly polymorphic locus $\mathrm{pspC}$ of Streptococcus pneumoniae. Gene 284,
63-71

23. Hammerschmidt, S., Talay, S. R., Brandtzaeg, P., and Chhatwal, G. S. (1997) SpsA, a novel pneumococcal surface protein with specific binding to secretory immunoglobulin A and secretory component. Mol. Microbiol. 25, 1113-1124

24. Hammerschmidt, S., Tillig, M. P., Wolff, S., Vaerman, J. P., and Chhatwal, G. S. (2000) Species-specific binding of human secretory component to SpsA protein of Streptococcus pneumoniae via a hexapeptide motif. Mol. Microbiol. 36, 726-736

25. Elm, C., Braathen, R., Bergmann, S., Frank, R., Vaerman, J. P., Kaetzel, C. S., Chhatwal, G. S., Johansen, F. E., and Hammerschmidt, S. (2004) Ectodomains 3 and 4 of human polymeric Immunoglobulin receptor (hpIgR) mediate invasion of Streptococcus pneumoniae into the epithelium. J. Biol. Chem. 279, 6296-6304

26. Zhang, J. R., Mostov, K. E., Lamm, M. E., Nanno, M., Shimida, S., Ohwaki, M., and Tuomanen, E. (2000) The polymeric immunoglobulin receptor translocates pneumococci across human nasopharyngeal epithelial cells. Cell 102, 827-837

27. Orihuela, C. J., Mahdavi, J., Thornton, J., Mann, B., Wooldridge, K. G., Abouseada, N., Oldfield, N. J., Self, T., Ala'Aldeen, D. A., and Tuomanen, E. I. (2009) Laminin receptor initiates bacterial contact with the blood brain barrier in experimental meningitis models. J. Clin. Invest. 119, $1638-1646$

28. Dave, S., Carmicle, S., Hammerschmidt, S., Pangburn, M. K., and McDaniel, L. S. (2004) Dual roles of PspC, a surface protein of Streptococcus pneumoniae, in binding human secretory IgA and factor H. J. Immunol. $173,471-477$

29. Dieudonné-Vatran, A., Krentz, S., Blom, A. M., Meri, S., Henriques-Normark, B., Riesbeck, K., and Albiger, B. (2009) Clinical isolates of Streptococcus pneumoniae bind the complement inhibitor $\mathrm{C} 4 \mathrm{~b}$-binding protein in a PspC allele-dependent fashion. J. Immunol. 182, 7865-7877

30. Hammerschmidt, S., Agarwal, V., Kunert, A., Haelbich, S., Skerka, C., and Zipfel, P. F. (2007) The host immune regulator factor $\mathrm{H}$ interacts via two contact sites with the PspC protein of Streptococcus pneumoniae and mediates adhesion to host epithelial cells. J. Immunol. 178, 5848-5858

31. Zipfel, P. F., Hallström, T., Hammerschmidt, S., and Skerka, C. (2008) The complement fitness factor $\mathrm{H}$ : role in human diseases and for immune escape of pathogens, like pneumococci. Vaccine 26, Suppl. 8, I67-I74

32. Preissner, K. T. (1991) Structure and biological role of vitronectin. Annu. Rev. Cell Biol. 7, 275-310

33. Preissner, K. T., and Reuning, U. (2011) Vitronectin in vascular context: facets of a multitalented matricellular protein. Semin. Thromb. Hemost. $37,408-424$

34. Felding-Habermann, B., and Cheresh, D. A. (1993) Vitronectin and its receptors. Curr. Opin. Cell Biol. 5, 864-868

35. Chillakuri, C. R., Jones, C., and Mardon, H. J. (2010) Heparin binding domain in vitronectin is required for oligomerization and thus enhances integrin-mediated cell adhesion and spreading. FEBS Lett. 584, 3287-3291

36. Hallström, T., Blom, A. M., Zipfel, P. F., and Riesbeck, K. (2009) Nontypeable Haemophilus influenzae protein E binds vitronectin and is important for serum resistance. J. Immunol. 183, 2593-2601

37. Hallström, T., Singh, B., Resman, F., Blom, A. M., Mörgelin, M., and Riesbeck, K. (2011) Haemophilus influenzae protein E binds to the extracellular matrix by concurrently interacting with laminin and vitronectin. J. Infect. Dis. 204, 1065-1074

38. Singh, B., Jalalvand, F., Mörgelin, M., Zipfel, P., Blom, A. M., and Riesbeck, K. (2011) Haemophilus influenzae protein E recognizes the C-terminal domain of vitronectin and modulates the membrane attack complex. Mol. Microbiol. 81, 80-98

39. Singh, B., Su, Y. C., and Riesbeck, K. (2010) Vitronectin in bacterial pathogenesis: a host protein used in complement escape and cellular invasion. Mol. Microbiol. 78, 545-560

40. Härtel, T., Klein, M., Koedel, U., Rohde, M., Petruschka, L., and Hammerschmidt, S. (2011) Impact of glutamine transporters on pneumococcal fitness under infection-related conditions. Infect. Immun. 79, 44-58

41. Asmat, T. M., Klingbeil, K., Jensch, I., Burchhardt, G., and Hammerschmidt, S. (2012) Heterologous expression of pneumococcal virulence 


\section{Pneumococcal PspC Binds Vitronectin}

factor PspC on the surface of Lactococcus lactis confers adhesive properties. Microbiology 158, 771-780

42. Haupt, K., Reuter, M., van den Elsen, J., Burman, J., Hälbich, S., Richter, J., Skerka, C., and Zipfel, P. F. (2008) The Staphylococcus aureus protein Sbi acts as a complement inhibitor and forms a tripartite complex with host complement Factor H and C3b. PLoS Pathog. 4, e1000250

43. Janulczyk, R., Iannelli, F., Sjoholm, A. G., Pozzi, G., and Bjorck, L. (2000) Hic, a novel surface protein of Streptococcus pneumoniae that interferes with complement function. J. Biol. Chem. 275, 37257-37263

44. Vengadesan, K., and Narayana, S. V. (2011) Structural biology of Grampositive bacterial adhesins. Protein Sci. 20, 759-772

45. Jensch, I., Gámez, G., Rothe, M., Ebert, S., Fulde, M., Somplatzki, D., Bergmann, S., Petruschka, L., Rohde, M., Nau, R., and Hammerschmidt, S. (2010) PavB is a surface-exposed adhesin of Streptococcus pneumoniae contributing to nasopharyngeal colonization and airways infections. Mol. Microbiol. 77, 22-43

46. Lin, I. H., Hsu, M. T., and Chang, C. H. (2012) Protein domain repetition is enriched in streptococcal cell-surface proteins. Genomics 100, 370-379

47. Hill, D. J., Whittles, C., and Virji, M. (2012) A novel group of Moraxella catarrhalis UspA proteins mediates cellular adhesion via CEACAMs and vitronectin. PLoS One 7, e45452

48. Chia, J. S., Yeh, C. Y., and Chen, J. Y. (2000) Identification of a fibronectinbinding protein from Streptococcus mutans. Infect. Immun. 68, $1864-1870$

49. Lowrance, J. H., Hasty, D. L., and Simpson, W. A. (1988) Adherence of Streptococcus sanguis to conformationally specific determinants in fibronectin. Infect. Immun. 56, 2279-2285

50. McNab, R., Holmes, A. R., Clarke, J. M., Tannock, G. W., and Jenkinson, H. F. (1996) Cell surface polypeptide CshA mediates binding of Streptococcus gordonii to other oral bacteria and to immobilized fibronectin. Infect. Immun. 64, 4204-4210

51. Tellier, M. C., Greco, G., Klotman, M., Mosoian, A., Cara, A., Arap, W., Ruoslahti, E., Pasqualini, R., and Schnapp, L. M. (2000) Superfibronectin, a multimeric form of fibronectin, increases HIV infection of primary CD4 ${ }^{+}$ T lymphocytes. J. Immunol. 164, 3236-3245

52. Hyams, C., Opel, S., Hanage, W., Yuste, J., Bax, K., Henriques-Normark, B., Spratt, B. G., and Brown, J. S. (2011) Effects of Streptococcus pneumoniae strain background on complement resistance. PLoS One 6, e24581

53. Hyams, C., Yuste, J., Bax, K., Camberlein, E., Weiser, J. N., and Brown, J. S. (2010) Streptococcus pneumoniae resistance to complement-mediated immunity is dependent on the capsular serotype. Infect. Immun. 78, $716-725$

54. Yuste, J., Khandavilli, S., Ansari, N., Muttardi, K., Ismail, L., Hyams, C., Weiser, J., Mitchell, T., and Brown, J. S. (2010) The effects of PspC on complement-mediated immunity to Streptococcus pneumoniae vary with strain background and capsular serotype. Infect. Immun. 78, 283-292

55. Hammerschmidt, S., Wolff, S., Hocke, A., Rosseau, S., Müller, E., and Rohde, M. (2005) Illustration of pneumococcal polysaccharide capsule during adherence and invasion of epithelial cells. Infect. Immun. 73, $4653-4667$

56. Weiser, J. N., and Kapoor, M. (1999) Effect of intrastrain variation in the amount of capsular polysaccharide on genetic transformation of Streptococcus pneumoniae: implications for virulence studies of encapsulated strains. Infect. Immun. 67, 3690-3692

57. Weiser, J. N., Markiewicz, Z., Tuomanen, E. I., and Wani, J. H. (1996) Relationship between phase variation in colony morphology, intrastrain variation in cell wall physiology, and nasopharyngeal colonization by Streptococcus pneumoniae. Infect. Immun. 64, 2240-2245

58. Petit, C. M., Brown, J. R., Ingraham, K., Bryant, A. P., and Holmes, D. J. (2001) Lipid modification of prelipoproteins is dispensable for growth in vitro but essential for virulence in Streptococcus pneumoniae. FEMS Microbiol. Lett. 200, 229-233

59. Holmes, A. R., McNab, R., Millsap, K. W., Rohde, M., Hammerschmidt, S., Mawdsley, J. L., and Jenkinson, H. F. (2001) The pavA gene of Streptococcus pneumoniae encodes a fibronectin-binding protein that is essential for virulence. Mol. Microbiol. 41, 1395-1408

60. Tettelin, H., Nelson, K. E., Paulsen, I. T., Eisen, J. A., Read, T. D., Peterson, S., Heidelberg, J., DeBoy, R. T., Haft, D. H., Dodson, R. J., Durkin, A. S., Gwinn, M., Kolonay, J. F., Nelson, W. C., Peterson, J. D., Umayam, L. A., White, O., Salzberg, S. L., Lewis, M. R., Radune, D., Holtzapple, E., Khouri, H., Wolf, A. M., Utterback, T. R., Hansen, C. L., McDonald, L. A., Feldblyum, T. V., Angiuoli, S., Dickinson, T., Hickey, E. K., Holt, I. E., Loftus, B. J., Yang, F., Smith, H. O., Venter, J. C., Dougherty, B. A., Morrison, D. A., Hollingshead, S. K., and Fraser, C. M. (2001) Complete genome sequence of a virulent isolate of Streptococcus pneumoniae. Science 293, 498-506

61. Gasson, M. J. (1983) Plasmid complements of Streptococcus lactis NCDO 712 and other lactic streptococci after protoplast-induced curing. J. Bacteriol. 154, 1-9

62. Ichihara, Y., and Kurosawa, Y. (1993) Construction of new T vectors for direct cloning of PCR products. Gene 130, 153-154 